\title{
Two centuries of demographic change in Canada
}

\author{
Barry Edmonston*
}

\begin{abstract}
One key aspect of the demographic transition — the shift from high mortality and high fertility to low mortality and low fertility - is a major change in the population's age distribution from a pyramidshaped young age structure to a pillar-shaped old age structure. This paper discusses two demographic processes affected by changes in age structure. First, there are effects on vital rates, with important differences in the observed crude rates and the implied intrinsic vital rates. Second, changes in age structure influence population momentum. More recently, demographers have noted that older age distributions associated with fertility levels below replacement have negative population momentum. Although the demographic transition has been well-described for many countries, demographers have seldom analyzed intrinsic vital rates and population momentum over time, which are dynamic processes affected by changes in the population age structure and which, in turn, influence future changes in population growth and size. This paper uses new data and methods to analyze intrinsic vital rates and population momentum across two centuries of demographic change in Canada.
\end{abstract}

Keywords: fertility, mortality, demographic transition, intrinsic vital rates, population momentum.

\section{Résumé}

Un aspect clé de la transition démographique, c'est-à-dire le passage d'une forte mortalité et forte fécondité à une faible mortalité et faible fertilité, représente un changement de taille dans la répartition par âge de la population, allant d'une structure pyramidale de jeunes à une structure en forme de piliers d'une population plus âgée. Cet article porte sur deux processus démographiques concernés par les changements démographiques par âge. D'abord, il y a des effets sur les indices vitaux avec des différences importantes dans les taux bruts observés et les taux vitaux intrinsèques. Puis, les changements dans la structure par âge influencent l'élan démographique. Tout dernièrement, les démographes ont remarqué que la répartition par âge plus avancé associée à un taux de fertilité inférieur au taux de remplacement a un effet négatif sur l'élan démographique. Bien que la transition démographique ait été bien décrite pour nombre de pays, les démographes ont rarement analysé les taux vitaux intrinsèques et l'élan démographique au fil du temps, c'est-à-dire qu'il s'agit de processus dynamiques concernés par les changements dans la structure par âge de la population ce qui a des conséquences sur la croissance et la taille des populations futures. Cet article fait appel à de nouvelles données et méthodes pour analyser les taux vitaux intrinsèques et l'élan démographique sur deux siècles de changements démographiques au Canada.

Mots-clés : fécondité, mortalité, transition démographique, les taux intrinsèque d'accroissement naturel, potential d'accroissment.

\section{Introduction}

In preparing this paper, my selection of the topic began when I reflected on the contributions of two great Canadian demographers, Nathan Keyfitz and Norman Ryder. I thought about their work that dealt with Canada's population and it immediately struck me that there were some common areas. Nathan Keyfitz (1950) published an article in Population Studies that dealt with the growth of Canada's population-his paper offered the first historical estimates of international migration

* Barry Edmonston, Department of Sociology and Population Research Group, University of Victoria, PO Box 3050 STN CSC, Victoria BC V8W 3P5. E-mail be@uvic.ca. 
for Canada - and he later pioneered the use of stable population theory to understand population momentum. Norman Ryder (1997) had a long-term interest in the stationary population model and had a noteworthy publication in Canadian Studies in Population on this topic.

Their work stimulated my thinking about building on the research of these two giants of demographic research. This paper examines two centuries of demographic change in Canada, using ideas from Ryder and Keyfitz, with new data and methods. The paper covers the following topics. First, it offers some background, using ideas of the demographic transition, to provide a framework for studying Canada's demographic changes. It highlights the contributions of four individuals-Alfred Lotka, Norman Ryder, Paul Vincent, and Nathan Keyfitz-because the paper's ideas owe a great debt to these demographic pioneers. Next, it turns to work on stationary population, noting Ryder's contributions to this topic, and shows how changes in intrinsic vital rates inform our understanding of demographic change. Third, it reviews work by Keyfitz and others on population momentum and illustrates how the components of momentum have evolved in Canada over its demographic transition. Finally, the paper ends with some concluding remarks.

\section{Background}

I begin by discussing the demographic transition, reviewing how recent research offers new perspectives on historical population changes in developed and developing countries. The demographic transition raises questions about what happened to vital rates and how concepts from stable population theory provide insight into demographic processes in Canada.

To carry out this study, we need data that are usually not available for longer time periods. For our analysis, we need information on populations by age and sex, age-specific fertility rates, and life tables by age. Fortunately, we have two sources. Based on my earlier work reconstructing Canada's population from 1851 to 2001, which presents new estimates for international migration, it provides the historical demographic data needed for 1851 to 2001 (Edmonston 2010a, 2010b). Coupled with Statistics Canada's population projections for 2011 to 2061, this provides the requisite information for studying 210 years of demographic change from 1851 to 2061.

Methods have been available for some time for calculating intrinsic vital rates and stable age distributions. Work by Samuel Preston (1986) and others, however, offers additional insight into the interpretation of intrinsic rates. We have lacked methods for disentangling the components of population momentum until two excellent recent papers by Thomas Espenshade and his colleagues (Espenshade et al. 2011; Blue and Espenshade 2011). I use Espenshade's work to document changes in the components of population momentum for Canada's historical data. These are useful insights, because we have heretofore lacked such information about Canada's demographic transition.

\section{Demographic transition}

Although there is considerable variation in the European demographic transition (Lee 2003), there are general patterns to the changes that occurred in European populations. The demographic transition first occurred in parts of Europe, when death rates began a steady decrease in the 1600s and 1700s. By the 1800s, mortality decreases were evident across Europe as industrialization took hold.

Although death rates were declining, birth rates initially remained steady. So for many decades, the number of births exceeded the number of deaths by a sizeable amount. European populations continued to grow because fertility remained moderately high until the late 1800s and early 1900s. 
After 1900, European fertility levels fell to replacement levels around mid-century, and have since fallen to well below replacement.

The demographic transition has occurred more rapidly in developing countries than in Europe. Rapid mortality declines in developing countries, accompanied by little or no decrease in fertility, have resulted in a shorter period of more rapid population growth - rather than the moderate growth experienced by European countries over a longer period.

Unlike Europe, rapid fertility declines followed mortality improvements within a few decades in developing countries. Although fertility has remained high in sub-Saharan Africa and parts of the Middle East, most other developing countries have completed the demographic transition. Indeed, every country in East Asia now has sub-replacement fertility, and even countries of previously high concern such as Bangladesh and Indonesia have fertility levels that are close to replacement.

The demographic transition, then, describes developing countries fairly well. The major differences between the experiences of Europe and developing countries are (1) the speed of the mortality decline, (2) the speed of fertility decline, and (3) more rapid population growth (these differences and others are discussed in Lee's useful 2003 paper).

\section{Patterns of demographic transition}

To illustrate some of the important patterns of demographic transition (see Figure 1), I use six stages in the figure. Stage 1 is pre-transition, with high and fluctuating crude death rates and high and approximately replacement crude birth rates. Population growth is negligible. The age distribution is pyramid-shaped and very young.

In stage 2 , death rates begin to fall while birth rates remain unchanged. This leads to fertility above replacement and moderate population growth. The age structure remains young.

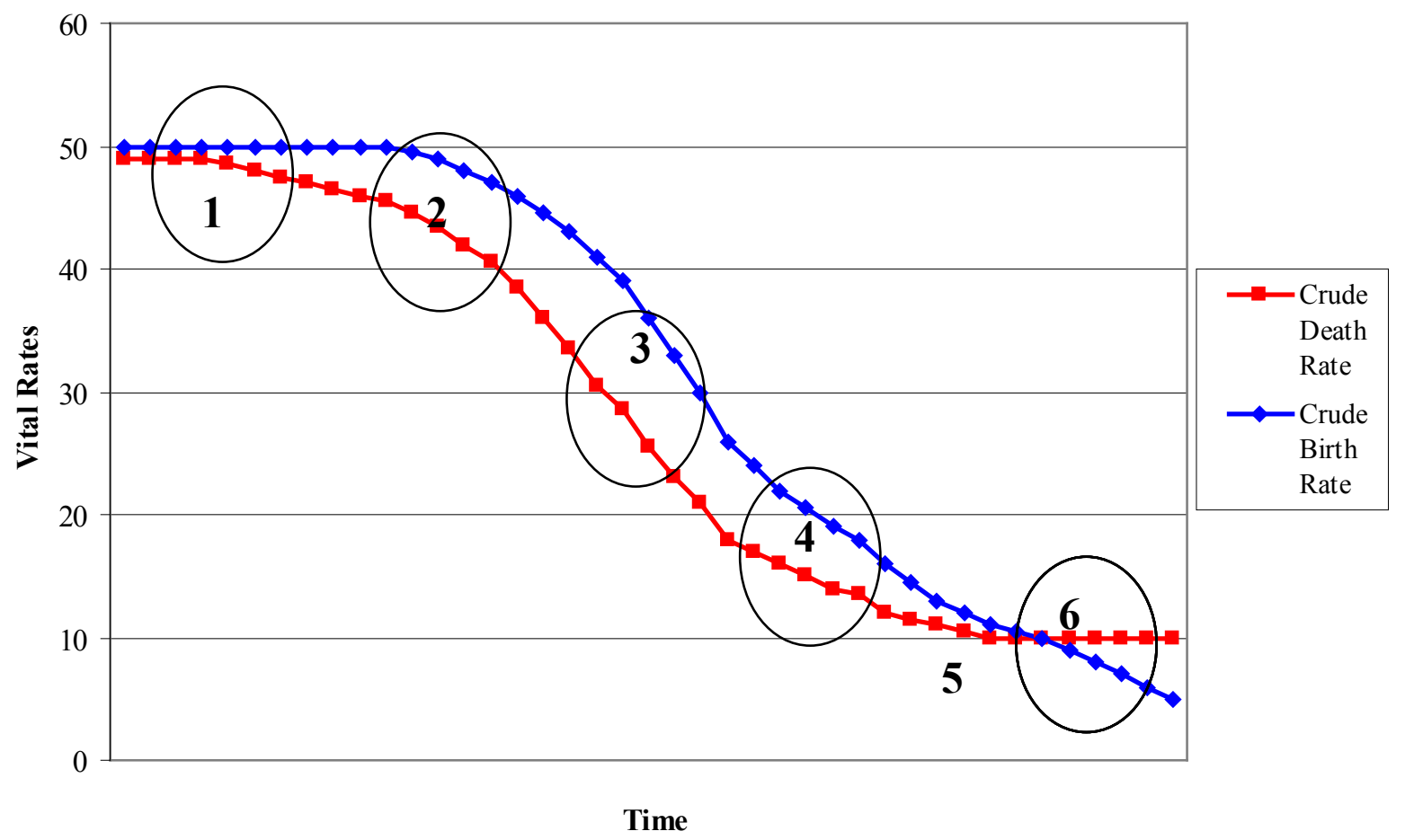

Figure 1. Patterns of the demographic transition. 


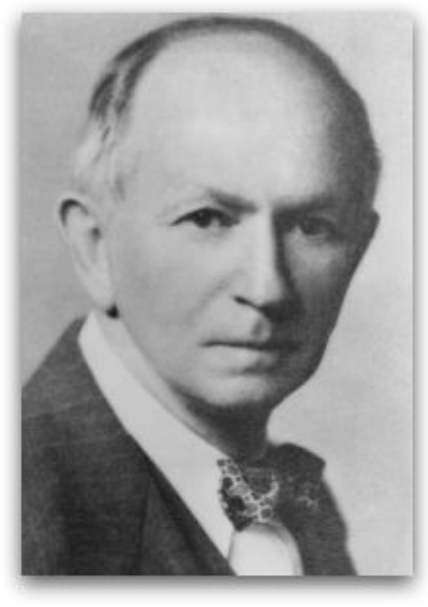

\section{Exhibit 1. Alfred James Lotka, 1880-1949.}

Alfred James Lotka was a very cosmopolitan scholar. He was born 2 March 1880 in Austria-Hungary, in the town of Lemberg, to French-German speaking parents who held U.S. citizenship. He was educated internationally, receiving a B.S. at University of Birmingham, England. He did graduate work at Leipzig University, and then received his M.A. at Cornell University and D.Sc. at the University of Birmingham in 1912. After receiving his doctorate, he moved to the United States, serving as an editor at Scientific American and a staff member at Johns Hopkins University before becoming a statistician for the Metropolitan Life Insurance Company, New York, where he worked from 1924 until his retirement in 1947.

While at Johns Hopkins, Lotka completed his book Elements of Mathematical Biology (1925). Although the book covered a large number of topics, it is primarily known today for the Lotka-Volterra equations of population dynamics.

In 1934 and 1939, Lotka published the two volumes of his Théorie analytique des associations biologiques (Analytical Theory of Biological Associations) in French, which summarizes his works on demography, and offers the first full statement of stable population theory.

He teamed up with Louis Dublin, another statistician at Metropolitan Life Insurance Company to write three books on demography and public health: Length of Life, published in 1936, is well-known to demographers for its comprehensive work on life tables.

In the view of Nathan Keyfitz, one of his most important successors, Lotka's work on the mathematics of stable populations is "the greatest single contribution to population theory." Although there has never been a "stable" population exhibiting all the relations worked out by Lotka and his successors, stable populations are useful constructs. They do not literally exist, but with a few assumptions and approximations, they can be used to make progress on practical problems otherwise too complex to approach. Lotka's work was also the foundation for what we know about the importance of momentum for future population growth. Stable population theory has been applied to thinking about stationary populations, a population which has a growth rate of zero.

In stage 3, there are decreases in both death and birth rates, but with birth rates greatly exceeding death rates. Population growth quickens. The age structure begins to change and there are proportionate decreases in the younger population.

During stage 4, there is low mortality and falling fertility, with fertility slightly above or at replacement. The population ages more rapidly, with proportionate decreases in the younger population and steady proportionate increases in the elderly population.

Stage 5 illustrates the period in which there is replacement fertility, which exists for some industrialized countries, such as France, Iceland, and the United States. Most industrialized countries, however, have not remained at replacement-level fertility; rather, they have experienced below-replacement fertility.

Stage 6 illustrates what has happened in many developed countries, with low death rates and subreplacement fertility. Although it is not clear that sub-replacement fertility is inevitable and will be sustained for long periods, it is now common in many developed countries, characterized by an older age distribution and population decline in the absence of net immigration. 


\section{Stable population theory}

With this brief background on the demographic transition, we discuss how concepts of stable population theory can help understand demographic dynamics in Canada (the excellent 1990 Lachapelle paper discusses several applications of stable population theory for Canada's population that are not emphasized here). Alfred Lotka introduced the concept of a stable population in the 1930s (Exhibit 1 describes Alfred Lotka's demographic contributions; biographical material for Lotka and Exhibits 3, 4, and 5 are from obituaries and testimonies posted on the internet).

A stable population is a population with zero net immigration in which age-specific fertility and mortality rates prevail for a long period of time. A stable population has unchanging vital rates and an unchanging age structure. It follows from this definition that a stable population will grow at a constant rate. There are, in fact, an infinite number of stable populations, ranging from high to low mortality, high to low fertility, high positive to high negative growth, and very young to very old age structures.

A special case of stable population occurs when replacement-level fertility exists. If the net reproduction rate for a population equals one, then over a long period of time the population will be stable but with zero population growth. This is an interesting concept because, as Ryder and others have shown, the stationary population offers a useful model for understanding population dynamics.

Lotka's work in the 1920s and 1930s was partially motivated by debates about population growth (Dublin and Lotka 1925). Lotka argued that observed crude rates did not correctly reveal underlying population processes. He noted especially that observed annual population growth rates in the United States did not show that fertility was actually below replacement level, and that if the situation continued, the population would eventually decline.

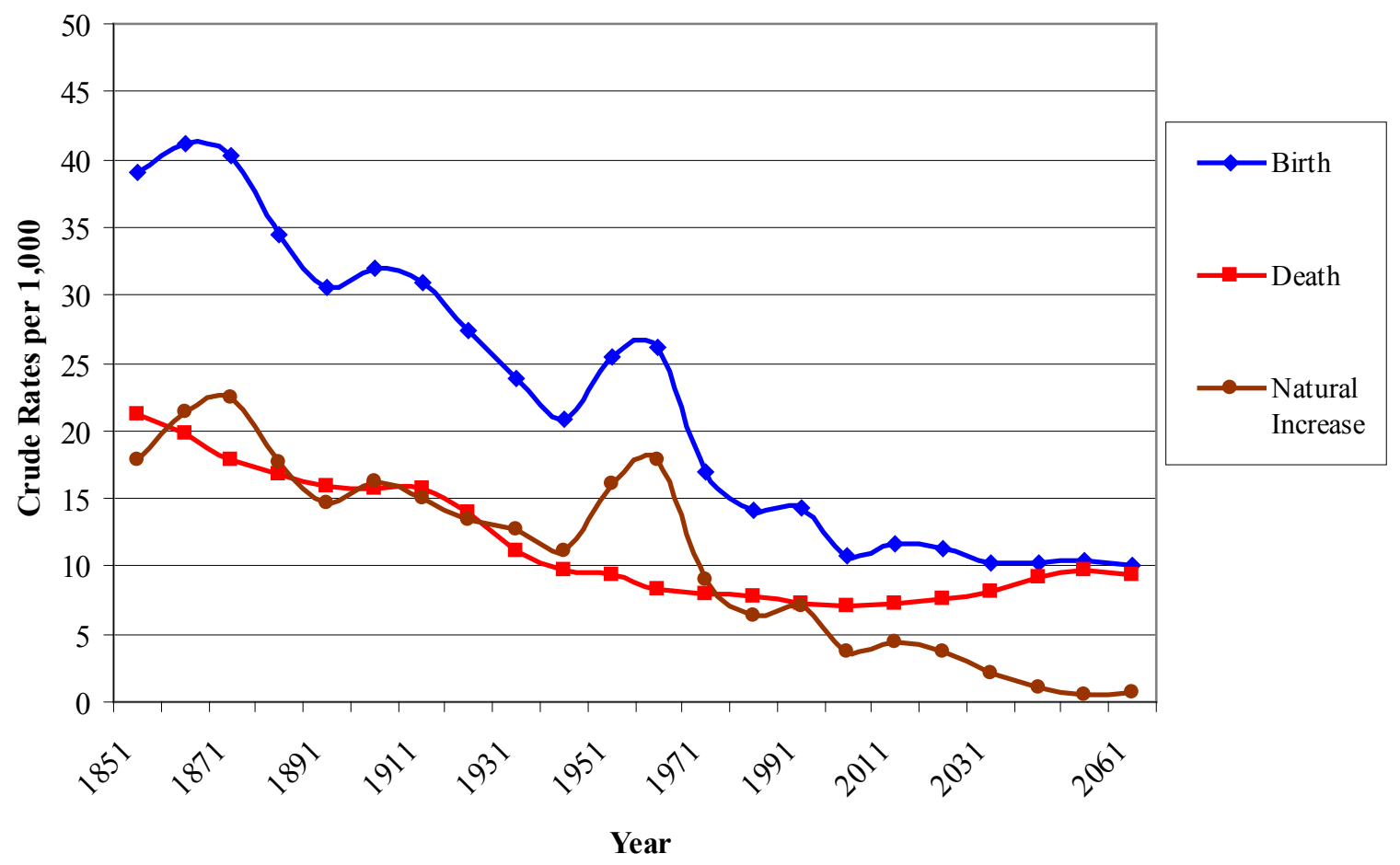

Figure 2. Crude birth and death rates and observed rate of natural increase: Canada, 1851-2061. 


\section{Exhibit 2. Intrinsic Vital Rates.}

The derivation and interpretation of intrinsic vital rates, as proposed by Alfred Lotka, is among the most useful practical aspects of stable population theory. Lotka's demonstration that a population with unchanging vital rates leads to a stable population provides a detailed indication of what current demographic rates imply for longer-term prospects.

If age-specific mortality rates-expressed as $p(a)$, the probability of surviving from birth to age $a$-are constant over time, age-specific fertility rates-expressed as $m(a)$, the probability of bearing a female child for women age $a$-are constant over time, net migration rates are zero for all ages, and $\alpha$ is the minimum age of childbearing and $\beta$ is the maximum age, then Lotka's proof leads to:

$$
1=\int_{a}^{\beta} e^{-r a} p(a) m(a) d a
$$

Equation 2.1 says that there is a unique value for $r$, the population's growth rate, associated with the observed $m(a)$ and $p(a)$ schedules. That is, there is a population growth rate intrinsic to any set of observed mortality and fertility schedules. We can calculate this intrinsic growth rate, $r$, from a set of age-specific mortality and fertility rates, demonstrating the long-term consequences of these rates for the population. Computational formulas are given at the end of this paper.

Lotka also derived equations characterizing a stable population, offering further information, including the intrinsic birth rate of a stable population:

$$
b=\frac{1}{\int_{a}^{\beta} e^{-r a} p(a) d a}
$$

where we integrate from birth, age 0 , to $\omega$, the highest age attained in the population. Equation 2.2 shows that there is a unique intrinsic birth rate associated with the intrinsic growth rate $r$ and the observed age-specific mortality rate.

Knowing the intrinsic growth and birth rate, the intrinsic death rate $d$ has a straightforward solution:

$$
d=r-b
$$

Finally, Lotka proved that the proportionate age distribution for a stable population is also unchanging:

$$
c(a)=b e^{-r a} p(a)
$$

The stable population might be decreasing, increasing, or experiencing zero growth. In all circumstances, however, the proportionate age distribution is constant. This means that, in a stable population, the proportion of elderly, 65 years or older, for example, will remain constant even if the total population is increasing or decreasing.

We next look at two centuries of observed rates of natural increase in Canada and compare them to the intrinsic rate of growth (see Exhibit 2 for background discussion of intrinsic vital rates). A fairly familiar demographic graph shows Canada's trends for crude birth and death rates, as well as observed rates of natural increase (see Figure 2). Figure 2 shows the crude birth rate was about 40 per 1,000 in the mid-1800s, declined steadily until the 1940s, increased sharply during the post-World War II baby boom, and recently declined to about 10 per 1,000, where it is projected to remain at this level to 2061. 
Edmonston: Two centuries of demographic change in Canada

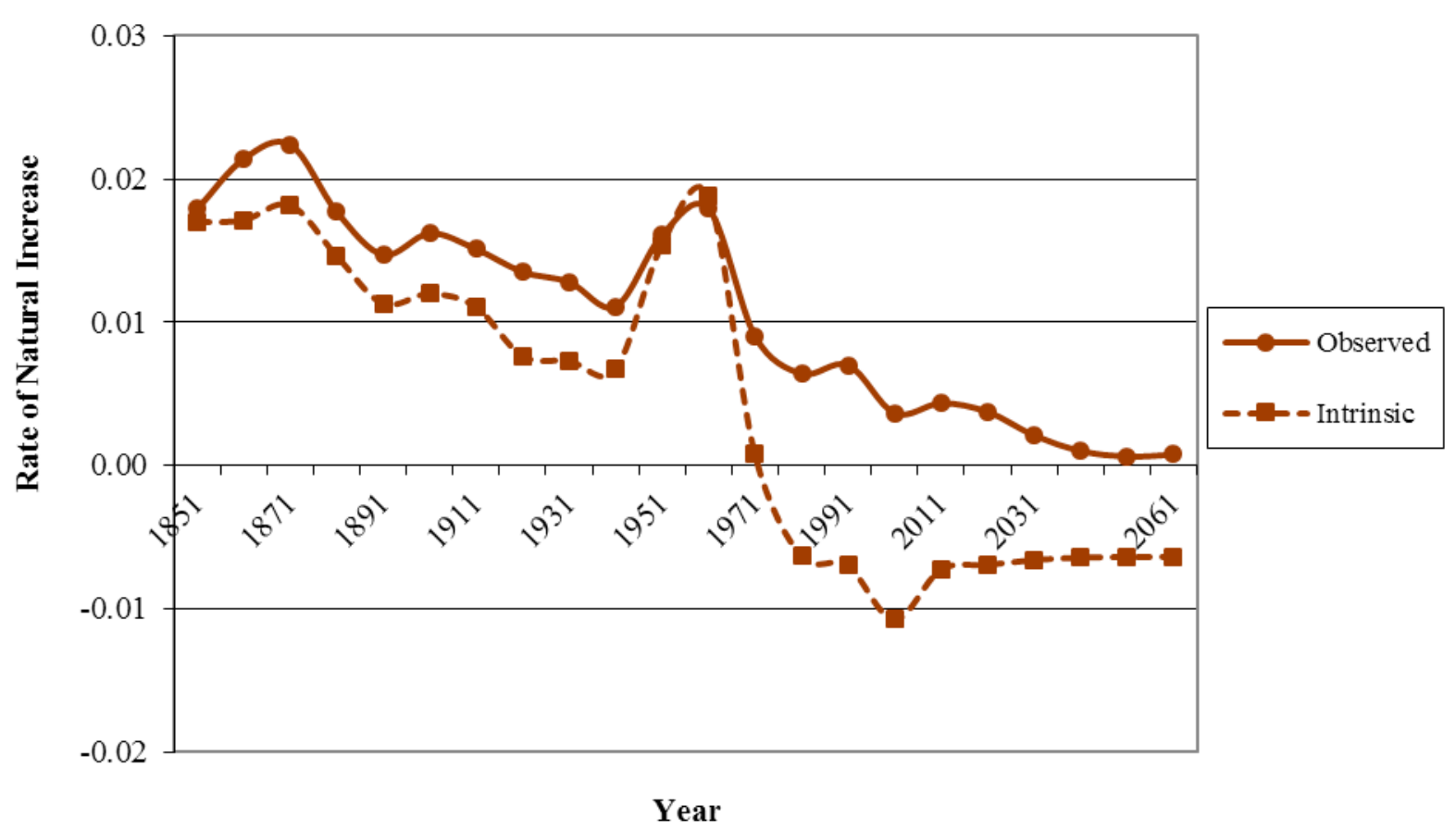

Figure 3. Crude and intrinsic rates of natural increase: Canada, 1851-2061.

The crude death rate decreased steadily from 1851 to 2011 and is projected to increase moderately as the population ages to about 15 per 1,000 in 2061. As a result of changes in the crude birth and death rates, observed rates of natural increase decreased from about 20 per 1,000 in the mid-1800s to about 10 per 1,000 in 1941, increased after World War II to about 20 per 1,000 in the 1960s, declined to about 5 per 1,000 in 2011, and rates are projected to diminish to approximately zero by 2051.

Long-term trends for intrinsic rates for Canada or other countries are seldom presented, however. The reason for the absence of trends for intrinsic rates, it seems, is that we rarely have comparable data on populations by age and sex, age-specific fertility rates, or, most importantly, period life tables. So, it is an interesting exercise to compare observed and intrinsic rates for a population over two centuries.

Figure 3 displays trends in the observed and intrinsic rates of natural increase. In general, the intrinsic rate of natural increase has been considerably lower than the observed rate of natural increase, except for the 1950s and 1960s. It is instructive to compare the observed and intrinsic rates for a specific period, for example the 1930s. The observed annual natural increase rate in Canada in the 1930s was about 1.3 percent, while the intrinsic growth rate was 0.8 . So, the intrinsic rate of natural increase was about one-half of one percentage point below the observed rate.

Why was the intrinsic rate of growth lower than the observed rate of natural increase? The main reason is that the observed age structure in the 1930s was younger than the intrinsic age distribution, as illustrated in Figure 4. Figure 4 shows Canada's observed 1931 population along with the stable age distribution implied by the long-term results of its age-specific mortality and fertility rates. The observed population has more females (and males) younger than 45 years and relatively more in the older years. The observed age distribution, relative to the stable age distribution, leads to higher crude birth rates, lower crude death rates, and higher rates of natural increase.

Lotka's insight into stable population theory was not that intrinsic rates are the only rates for demographic analysis. Rather, when age-specific mortality and fertility rates are changing and the observed age structure is noticeably affected by past trends in vital rates, then analysis needs to examine 


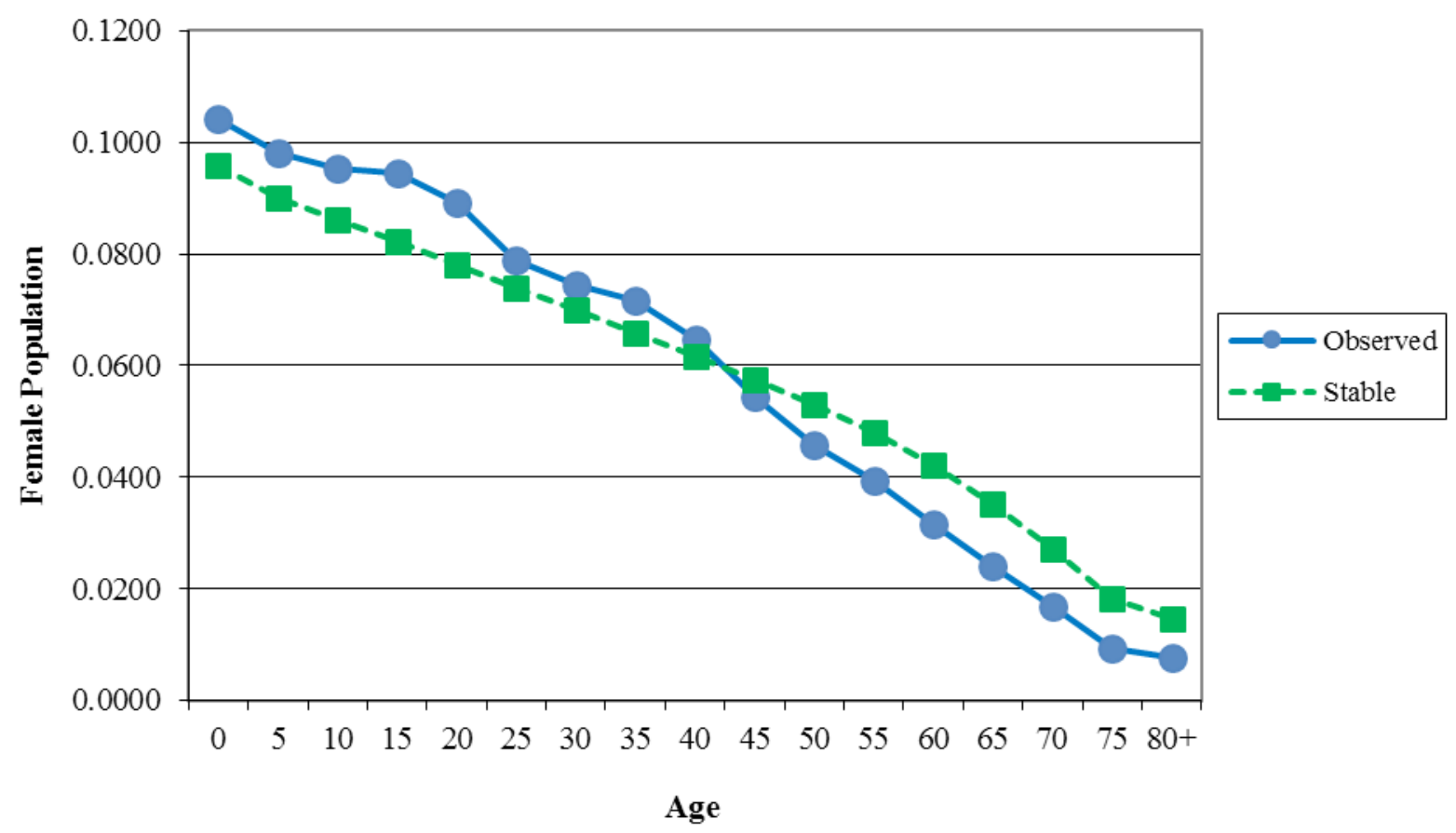

Figure 4. Observed and stable population age distribution: Canada, 1931.

both crude and intrinsic rates, with careful consideration of age distribution effects.

Returning to trends in the observed and intrinsic growth rate (see Figure 3), we can compare crude and intrinsic birth and death rates over time to learn more about the two components of natural increase. The intrinsic age structure reflects the long-term consequences of current age-specific vital ages. In other words, the intrinsic stable age structure and intrinsic vital rates tell us how the population would evolve over, say, the next century. The observed age structure, however, is a product of vital rates (and international migration) during the past century. So, we have two very different comparisons when we examine the observed and stable populations: the observed age structure reflects past demographic processes and the stable age structure demonstrates the long-term consequences of current vital rates.

For Canada from 1851 to 1951, the observed rate of natural increase exceeds the intrinsic rate substantially (see Figure 3). This occurred because fertility was decreasing and the observed age structure was younger than the stable age distribution--something that we saw earlier for the 1931 population. In the post-World War II decades, however, age-specific fertility rates increased dramatically and the observed and stable age distributions, on average, produce similar rates of natural increase. As age-specific fertility rates declined sharply after the mid-1960s, the intrinsic growth rate dropped and has been negative since the late 1970s. The observed rate of natural increase is projected to slowly decrease and become close to zero by about 2051.

Natural increase results from the difference between two demographic components: the birth rate and the death rate. For the birth rate, the observed crude birth rate has usually been slightly higher than the intrinsic birth rate (see Figure 5) and this is projected to continue. This has occurred because the observed age structure is younger than the stable age structure and, in particular, the observed age distribution has slightly more women in the childbearing years than the stable age structure. The observed age distribution is also affected, of course, by international migration. For the projected period to 2061, the crude birth rate is about 2 per 1,000 points higher because international migration continues to add younger adults to Canada's age distribution. 
Edmonston: Two centuries of demographic change in Canada

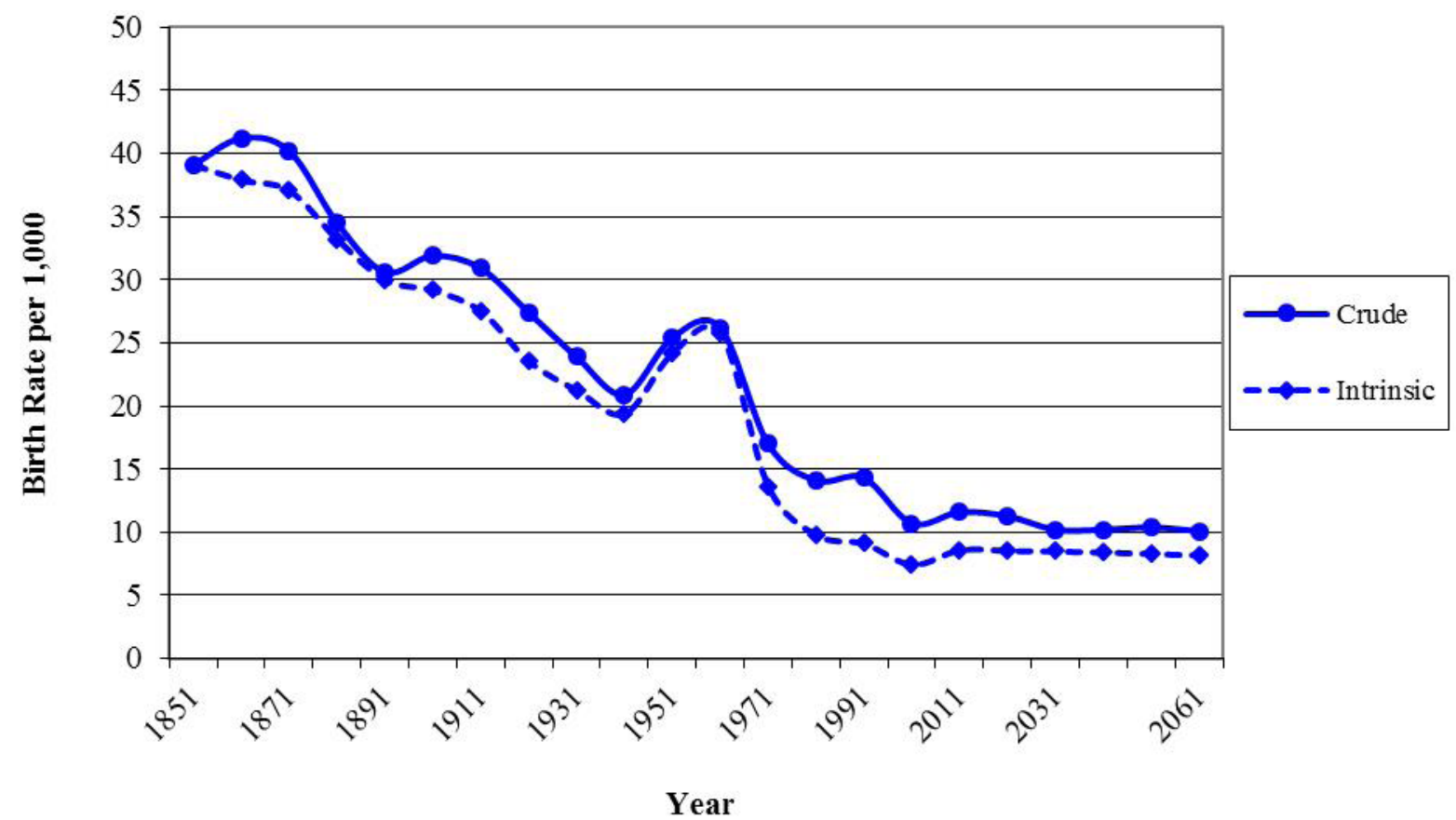

Figure 5. Crude and intrinsic birth rates: Canada, 1861-2061.

Comparison of the crude and intrinsic death rate (see Figure 6) shows differences that are also influenced by the age structure. The intrinsic death rate was higher than the crude death rate until the post-World War II period. In recent years and projected to 2061, the intrinsic death rate continues to be somewhat higher, reflecting the older stable age distribution compared to the observed age distribution.

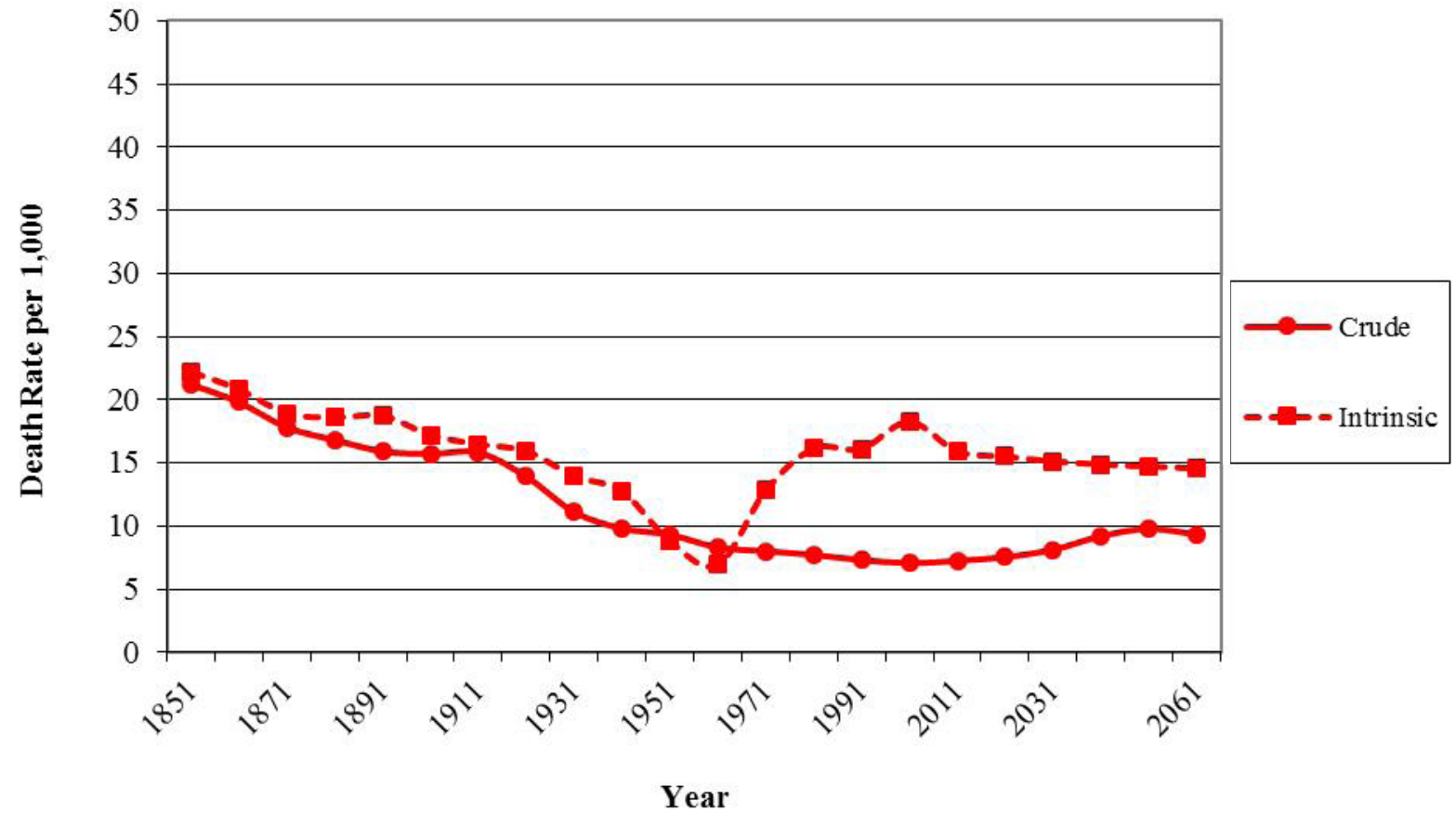

Figure 6. Crude and intrinsic death rates: Canada, 1851-2061. 


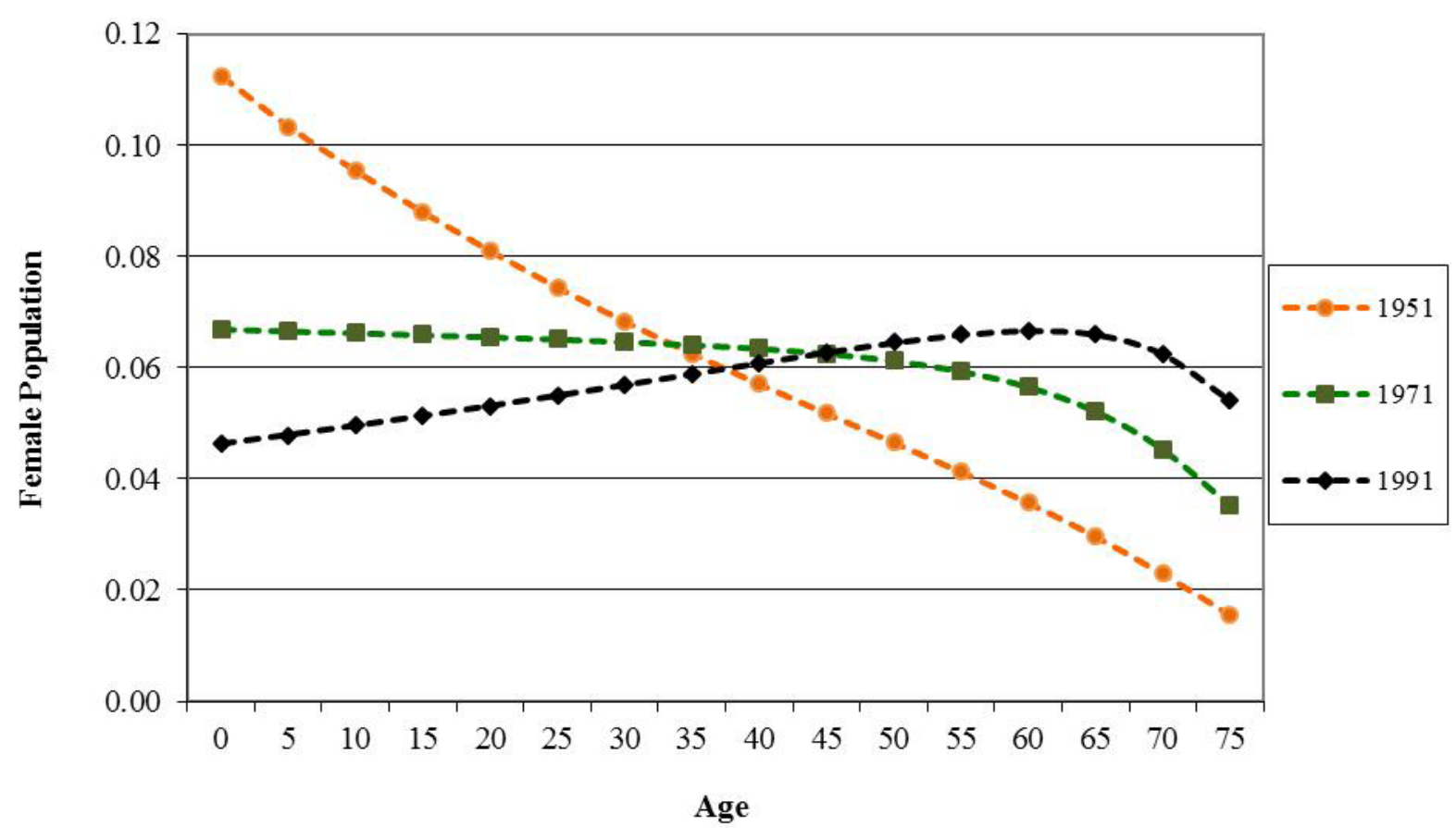

Figure 7. Stable Age Distributions: Canada, 1951, 1971, and 1991.

The stable age distributions for 1951, 1971, and 1991 (see Figure 7) demonstrate how the stable age distribution influences the death rate. In 1951, with fertility levels considerably above replacement level (the total fertility rate was 3.54, implying that a hypothetical woman experiencing the age-specific fertility rates of 1951 would have 3.54 children by the end of her childbearing years), the stable age distribution was pyramid-shaped and relatively young. By 1971, fertility levels had decreased (the total fertility was 2.15 and very close to replacement) and the stable age distribution was comparable to the one that we would see in a stationary population. The 1971 age distribution was pillar-shaped, with about the same number of persons at each age group from birth to about 55 years. In 1991, fertility levels decreased to below replacement level (the total fertility rate was 1.65, or about 20 percent below replacement), and the stable age distribution shows the effect of low fertility, with a much higher proportion of the population in the older years. Because of these changes in the stable age distribution, the intrinsic death rate almost doubled, from 8.8 per 1,000 in 1951 to 16.1 per 1,000 in 1991. These changes in the stable age distribution help us to understand why the intrinsic death rate increased dramatically from 1951 to 1991, and why the intrinsic death rate is projected to exceed the crude death rate for several decades, even as the population slowly ages.

\section{Stationary population}

A stationary population has more than academic interest. The average rate of population growth over long periods of history has been close to zero and, to minimize the possibility of the demise of our species, must hold at zero over the infinite future (Coale 1974). It is therefore of interest to consider the conditions for stationarity, qualifications about a stationary population, and comparison of demographic processes to the stationary population model.

The conditions for a stationary population are the same as for a stable population, except that replacement-level fertility prevails. Demographers commonly use the net reproduction rate (NRR) for measuring replacement fertility. NRR is a measure of the average number of daughters that fe- 


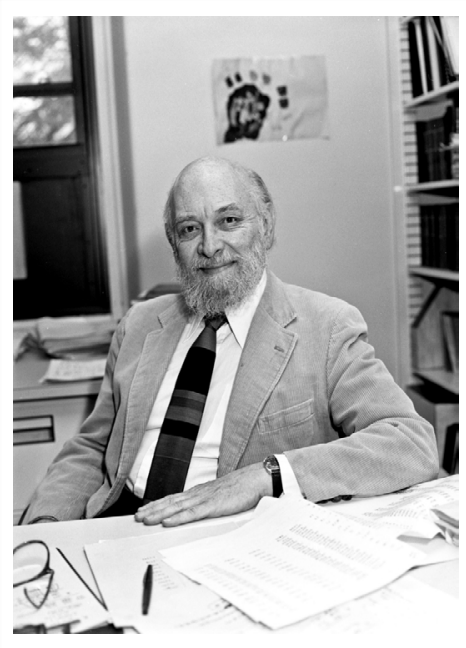

Exhibit 3. Norman Ryder, 1923-2010.

Norman Ryder was born 23 August 1923 in Hamilton, Ontario. He earned a bachelor's degree from McMaster University and a master's degree from the University of Toronto, both in political economy. After serving as a commissioned officer in the Canadian Naval Volunteer Reserve during World War II, he went to Princeton University, where he received a master's in economics in 1949 before earning his doctorate in sociology in 1951.

Ryder was a demographer with the Scripps Foundation for Research in Population, and a sociology faculty member at the University of Toronto, the University of Wisconsin-where he founded the Center for Demography and Ecology, and Princeton University.

Ryder was a seminal figure in the field of demography. Beginning with work during his graduate studies at Princeton in the 1950s, he established the "cohort" approach-studying a group of people born in the same period of time who go through life together and share common experiences - that has guided demographic research in the decades since. Ryder was fond of remarking, "One of my main missions in life has been to be a salesman for cohort analysis."

Before and during his time at Princeton, Ryder collaborated with Princeton sociologist Charles Westoff to co-found and co-direct the National Fertility Studies, an influential series of surveys conducted in 1965, 1970, and 1975.

Ryder's work was driven by his zeal for identifying probing questions related to social issues and developing exacting research agendas for himself and his colleagues to pursue. He was methodologically rigorous and approached social change from a mathematical perspective. One topic that interested Ryder over many years was the idea of a stationary population, which he explored in several papers, including a 1997 article that examines the influence of fertility, mortality, and migration on Canada's stationary population.

male members of a birth cohort would bear during their reproductive life span. If NRR is greater than 1.0, say 1.5, then a cohort of 100 women will leave behind a larger cohort of 150 daughters; if NRR is less than 1.0, say 0.7 , then a cohort of 100 women will leave behind a smaller number of 70 daughters; and if NRR equals 1.0, then a cohort of 100 women will leave behind exactly 100 daughters. Note that an NRR of 1 is actually the production of two functions: survival and fertility. If the chances for survival of women are low, then fertility needs to be higher in order to insure replacement-level fertility. For stationary population analysis, the survival and maternity functions for females are assumed to be fixed -- that is, unchanging for a long period of time. The stationary population also requires a fixed ratio of male to female births and a fixed survival function for males. Lastly, the original formulation of a stationary population assumes a population closed to migration.

Works by Norman Ryder $(1975,1997)$ and others have noted three important qualifications for thinking about stationary populations (Ryder's demographic contributions are highlighted in Exhibit 3). First, there are many different combinations of mortality and fertility schedules that can produce replacement-level fertility. Low survival counterbalanced by high fertility produces "inefficient" replacement because many births never reach the childbearing years. A situation of high survival and low fer- 
tility, as currently exists in Canada, yields "efficient" replacement because most female births complete the childbearing years. The central question of demographic concern, as emphasized by Ryder, is not the size of a stationary population, but whether it is the result of efficient or inefficient replacement.

Second, it is necessary but not sufficient for a stationary population to have a net reproduction rate equal to one. A, NRR equal to one produces a constant stream of births. But, to have a stationary population, the number of persons alive at each age needs to be constant, and this can occur only if the survival function remains constant. If the net reproduction rate equals one but expectation of life at birth is rising, then the population will continue to grow.

Third, although the original formulation of stable population theory assumed a population closed to migration, the assumption can be relaxed (Espenshade et al. 1982; Cerone 1987; Feichtinger and Steinmann 1992; Pflaumer 1993). From a theoretical point of view, a stationary population can accommodate a fixed volume and age distribution of migrants by redefining the survival function. If net migration is positive, the survival function is higher and if net migration is negative, then the survival function is lower. In each case, a stationary population is obtained by redefining the maternity functions in terms of the adjusted survival function to obtain a net reproduction rate of unity.

One of the most interesting and useful applications of stationary population relates to age composition, as noted in Ryder's (1997) study of Canada's population. A later section of this paper shows that when a growing stable population has fertility immediately reduced to replacement (with NRR equal to 1.0), the population will eventually become a stationary population with a rate of natural increase equal to 0 and a fixed population size. This situation has three important consequences. First, the age distribution of the stationary population is well-known: it is the same as the life table derived from the current population, because when the rate of natural increase $r$ equals 0 , the stable age distribution depends only on the survival function. Lotka derived the stable age distribution $c(a)$ as:

$$
c(a)=b e^{-r a} p(a),
$$

where $b$ is the intrinsic birth rate and $p(a)$ is the probability of living from birth to age $a$.

If $r$ equals 0 , then $e^{-r a}$ equals 1.0 and the stationary age distribution is:

$$
c(a)=b \cdot p(a)
$$

Equation (2) shows that the stationary age distribution $c(a)$ solely depends on $p(a)$, the probability of births $b$ surviving to age $a$, which is the life table formula for the number of persons alive at age $a$.

The second consequence is that a young population with NRR exceeding 1.0 will continue to increase for some time before obtaining zero growth as a stationary population. This continued growth, called population momentum, is discussed in greater detail below.

Ryder (1997) emphasized a third important consequence of a stationary population's age composition. Since a stationary population has an unchanging population age distribution and is constant in size, the number of persons at each age is also constant. The intrinsic birth rate $b$ of a stationary population must equal the intrinsic death rate $d$, because the intrinsic rate of natural increase is 0 . Thus,

$$
b=d=1 / e_{0} \quad,
$$

because the life table death rate equals the reciprocal of life expectancy at birth. Substituting $1 / e_{0}$ for $b$ in equation (2) produces an interesting expression for the age distribution, c(a), in a stationary population:

$$
c(a)=1 / e_{0} \cdot p(a)
$$


Edmonston: Two centuries of demographic change in Canada

This relatively simple relationship between the life table's values for $e_{0}$ and $p(a)$, and the stationary population age distribution is used now to analyze four population models. Ryder (1997) proposed three models for the study of Canada's 1994 population:

1. A population closed to migration, with the observed mortality and fertility. He called this the current fertility model.

2. A population closed to migration, but with replacement-level fertility and current mortality. He called this the replacement fertility model.

3. A population with current fertility and mortality but with international migration raised to compensate for sub-replacement fertility, which he called the replacement migration model.

I add a fourth model for consideration:

4. A population with current international migration and mortality, but with fertility raised to compensate for sub-replacement fertility. I call this the fill-the-gap fertility model.

We illustrate age distribution results for these four models for Canada's 2011 population. Note that the first model has current fertility and no net international migration. For Canada's 2011 population, the currently low fertility $(\mathrm{NRR}=0.81)$ means that the population will decrease in the futurehalved every 86 years - and will eventually become a declining stable population if there is no net migration. Replacement fertility assumes that age-specific fertility rates are adjusted proportionately, with an unchanging mean age at childbearing. More complicated models could be used, with alternative mean ages of childbearing, although modest differences in the age schedule of fertility would have a small influence on these results. Current and replacement migration assumes the age-sex distribution of international migrants arriving and departing Canada during 2001 to 2006. The replacement migration model adjusts immigration, holding emigration at 2011 levels. The final three models will become stationary populations, with zero population growth, through a combination of fertility, mortality, and migration processes.

Ryder (1997: 4) emphasized that the value of examining these types of population models has a descriptive policy purpose. He noted: "Models of the future based on fixed processes of population change cannot pretend to be realistic. They do however serve the descriptive purpose of showing the structural consequence of current behaviour."

Ryder (1997) proposed three age indices for the examination of his population models. Values of these indices for the four population models are shown in Table 1. The first index is the dependency ratio, calculated as the ratio between the number in the non-working ages ( 0 to 19 years plus 60 years and older) to the number in the working ages (20 to 59 years). The 2011 dependency ratio of 0.746 rises for the ultimate value of each of the four population models. The cause of future change, as noted by Ryder (1997), is that post-World War II children will become seniors in the next few decades, raising the dependency ratio. The current fertility model has the highest ultimate dependency ratio, because long-term sub-replacement fertility leads to a much older population, with a higher proportion of the elderly. A population with replacement fertility and no migration has a slightly lower dependency ratio than the other two replacement models. This comparison has the important policy implication that achieving a stationary population through migration produces a higher dependency ratio than one achieved through replacement fertility and zero migration.

The second index is the proportion of very old seniors, calculated as the ratio of the number of very old (aged 80 years and older) to the number of elderly (aged 60 years and older). Compared to the 2011 level—with 19.6 percent very old seniors of all elderly — the proportion of seniors who 
Table 1. Age Distribution Indices for Four Ultimate Population Scenarios, Canada 2011.

\begin{tabular}{lccccc}
\hline & & \multicolumn{4}{c}{ Ultimate population } \\
\cline { 3 - 6 } & $\begin{array}{c}2011 \\
\text { Population }\end{array}$ & $\begin{array}{c}\text { Current fertility, } \\
\text { no migration }\end{array}$ & $\begin{array}{c}\text { Replacement } \\
\text { fertility, no } \\
\text { migration }\end{array}$ & $\begin{array}{c}\text { Fill-the-gap } \\
\text { fertility, current } \\
\text { migration }\end{array}$ & $\begin{array}{c}\text { Current fertility, } \\
\text { replacement } \\
\text { migration }\end{array}$ \\
\cline { 2 - 6 } $\begin{array}{l}\text { Dependency ratio } \\
\begin{array}{l}\text { Percentage of very old } \\
\text { seniors }\end{array}\end{array}$ & 0.746 & 1.124 & 1.014 & 1.011 & 1.008 \\
$\begin{array}{l}\text { Labour force birth rate } \\
\text { (per 1,000) }\end{array}$ & 22.0 & 25.5 & 22.8 & 23.0 & 23.1 \\
\hline
\end{tabular}

Notes:

Dependency ratio equals the number of persons aged 0 to 19 years added to the number of persons aged 60 years and older, divided by the number of persons aged 20 to 59 years.

Percent of very old seniors equals the number of persons aged 80 years or older divided by the number of persons aged 60 years and older.

Working ages birth rate per 1,000 involves two different calculations. For the model closed to migration, it equals the number of persons aged 0 to 39 years, divided by 40 times the number of persons aged 20 to 59 years. For the migration replacement model, the previous rate is supplemented by the ratio of migrants aged 20 to 59 years to the population aged 20 to 59 years.

See text for description of ultimate population models.

are very old increases over time for each of the four models. The proportion of very old seniors increases the most for the current fertility model, with more than one-fourth the elderly population aged 80 years and older eventually. For the other three models, the proportion of very old reaches about 23 percent ultimately, and does not vary greatly between the models.

The third index proposed by Ryder (1997: 14) is a measure of the working ages birth rate, which indicates the rate of inflow into the working ages. For this age index, there are great differences among the four models and the current situation. The current rate of 22 (meaning that each year there will be 22 new entrants per 1,000 persons in the working ages) is similar to the rate for the ultimate population assuming replacement fertility. The effect of migration, however, alters the comparison to the current 2011 situation: the working ages birth rate is higher for all models involving migration, and the highest value, 28 , exists for the ultimate population assuming current fertility and replacement migration.

Overall, this example illustrates the types of useful insights that can be drawn from stationary population analysis. Different assumptions about levels of fertility and migration have strong effects on Canada's long-term age distribution. The dependency ratio increases for all four models, and to the highest level if current fertility continues with zero net migration. The proportion of elderly who are very old also increases markedly over time, especially if current fertility and no migration continue. The working ages birth rate increases somewhat with replacement fertility, replacement migration, or current migration and fill-the-gap fertility. Replacement migration leads to the highest inflow levels into the working ages.

\section{Relationship between Intrinsic Rate of Growth and Net Reproduction Rate}

Both the intrinsic rate of growth and the net reproduction rate provide measures of long-term population growth, assuming that current fertility and mortality rates remain constant. Moreover, both rates require exactly the same data: age-specific mortality and fertility rates. The net reproduction rate (NRR) can be defined as:

$$
N R R=\int_{\alpha}^{\beta} p(a) m(a) d a,
$$

where $p(a)$ is the probability of a female living to age $a$ and $m(a)$ is the probability of having a female 
birth at age $a$, over a woman's childbearing years from minimum age $\alpha$ to the end of childbearing at age $\beta$. Similarly, the equation for the intrinsic rate of natural increase $r$ is:

$$
\int_{\alpha}^{\beta} e^{-r a} p(a) m(a) d a=1
$$

Note that $e^{-r a}$ equals 1.0 in equation (6) if $r=0$, and hence,

$$
\int_{\alpha}^{\beta} p(a) m(a) d a=1
$$

which has the same expression on the left-hand side as equation (5), and hence, indicates that NRR must equal 1 if $r$ equals 0 . Equation (7) shows that NRR equals 1 when the intrinsic rate of natural increase equals 0 . It follows, by definition, that:

$$
\begin{aligned}
& \text { If } \mathrm{NRR}>1.0 \text {, then } r>0 . \\
& \text { If } \mathrm{NRR}=1.0 \text {, then } r=0 . \\
& \text { If } \mathrm{NRR}<1.0 \text {, then } r<0 .
\end{aligned}
$$

In studying the relationship between NRR and $r$, Lotka derived the expression:

$$
N R R=e^{r T}
$$

where $T$ is the mean length in years between population generations. In practice, the value for $T$ is close to the mean of childbearing in the stable population. Rearranging equation (8) and solving for $r$ gives:

$$
r=\ln (N R R) / T
$$

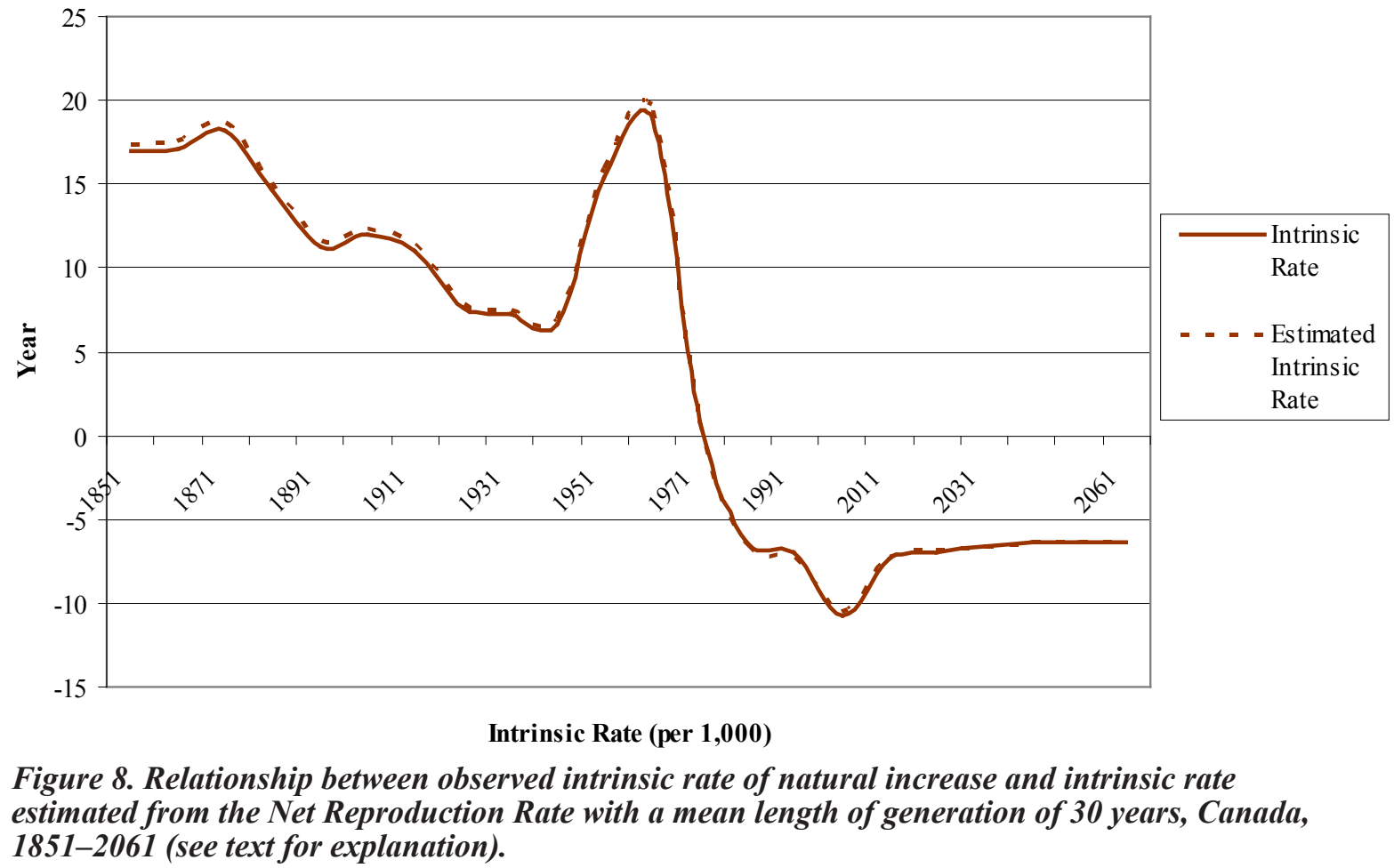


Empirically, $T$ generally lies between 26 and 34 years. Using the approximation for Canada's population of $T=30$ (the observed mean of childbearing in 2011 was 29.72 years), we can estimate Canada's approximate rate of natural increase as $\ln (\mathrm{NRR}) / 30$. As shown in Figure 8 , there is a very close relationship between the observed intrinsic rate of natural increase and intrinsic rate estimated on the basis of NRR, demonstrating that Lotka's empirical formula provides a close approximation of the theoretical relationship.

\section{Four population types}

Before turning to the concept of population momentum, we can use stable and stationary population ideas to describe four population types (see Figure 9). First, we have the observed population. For this example, the observed population is Canada's population in 2011 and is labelled $P$. Second, we calculate the stable population equivalent $Q$, which is implied by Canada's 2011 age-specific fertility and mortality rates, and the number of women aged 0 to the end of the childbearing years (the stable population equivalent is defined and described below). This population will have a stable age structure but with the stable population equivalent size. Next, we project both the observed and stable populations forward, assuming replacement level fertility and zero net migration. In each case, they become stationary populations. The observed population projected forward is $S_{1}$ and the stable population projected forward is $S_{2}$.

What do these four populations look like? The observed population of Canada in 2011, P, was 34.5 million. If the 2011 population were to have replacement-level fertility and current mortality-assuming zero net immigration - the population would increase in the next decades to a peak of 37.0 million in 2031 before decreasing to a constant 34.3 million in about 150 years. The final stationary population is labelled $S_{1}$.

Current 2011 fertility and mortality rates imply a stable population of 42.9 million, which Keyfitz called the stable population equivalent and called it $Q$. If we project the stable population equivalent under the assumption of replacement-level fertility, the final stationary population is labelled $S_{2}$.

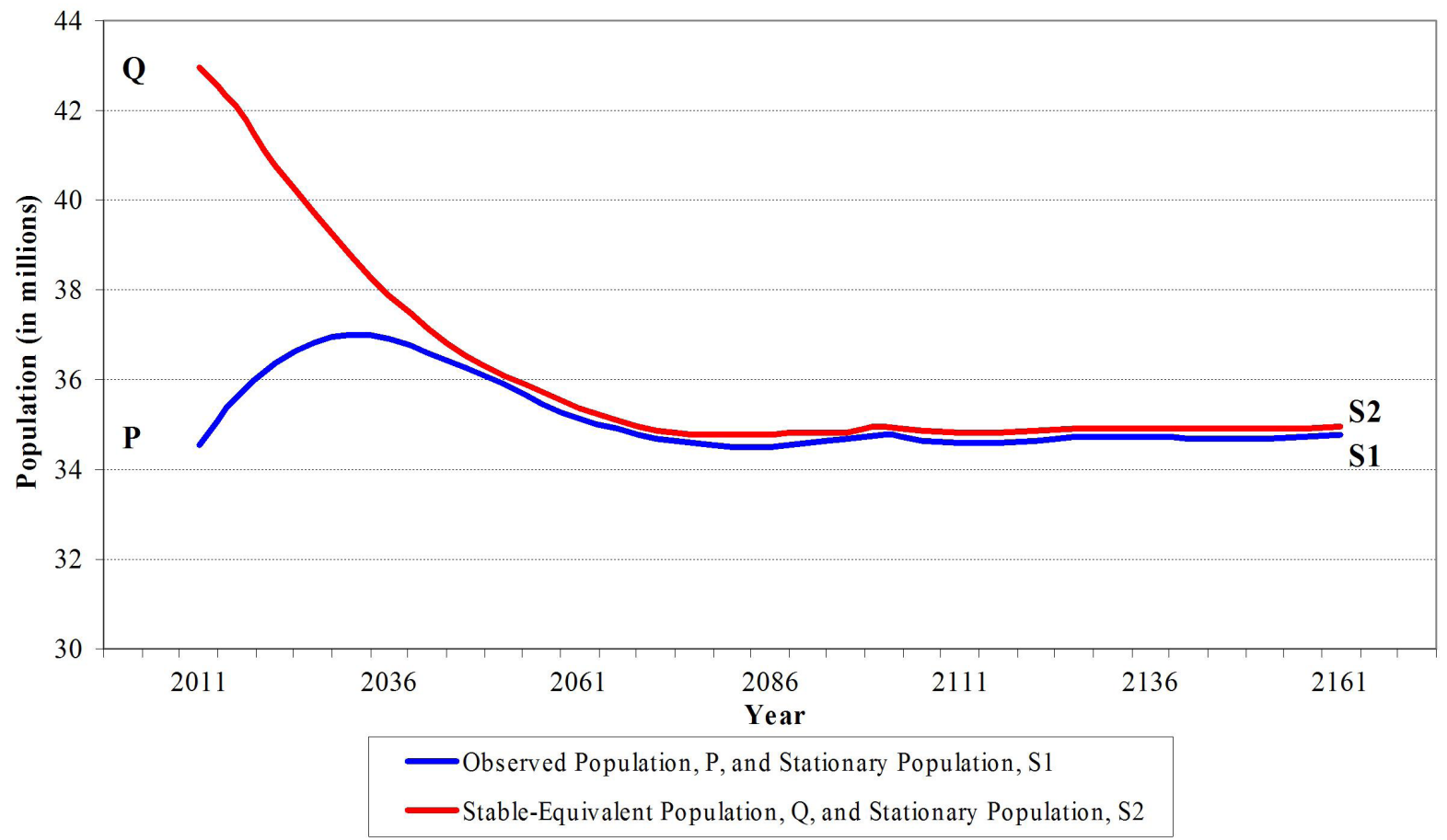

Figure 9. Four population types: Canada, 2011. 
We would expect that $S_{1}$ and $S_{2}$ would be similar, and indeed, $S_{2}$ equals 34.4 million, or only about 100,000 more than $S_{1}$. Differences between $S_{1}$ and $S_{2}$ are generally modest. Later discussion explains why $S_{1}$ and $S_{2}$ are usually very similar to each other.

With these concepts in mind, population momentum is discussed in the next section.

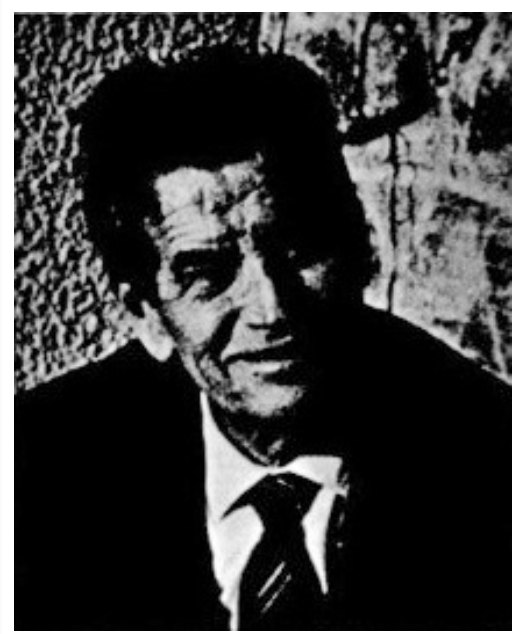

\section{Exhibit 4. Paul Vincent, 1912-1979.}

Paul Vincent was born 4 November 1912 in Beauforten-Vallée (Maine-et-Loire). He graduated from Ecole Polytechnique in 1931, receiving a law degree in Public Law and Political Economy. After graduation, he worked at a company manufacturing and selling tabulating equipment. Paul Vincent later served as a French officer in World War II.

In early 1943 he joined the National Foundation for the Study of Human Issues, led by Alexis Carrel. After Libération, when Institut national d'études démographiques (INED) was created under the leadership of Robert Debre and Alfred Sauvy, he was among the early young researchers who joined the staff at the Institute. At the end of 1945, he became Section Head of quantitative and demographic studies, which included what are now some of France's most famous demographers: Jean Bourgeois-Pichat, Louis Henry, Sully Ledermann and Leon Tabah. Manager, then Director of Research, Paul Vincent led an active group in research, scientific discussion, and teaching. He established the INED demography school in 1948, which has trained most French demographers.

Most of his work was on demographic processes and population projections. His main contributions to basic research included: (a) growth potential of a population; (b) mortality among the elderly and estimation of human longevity; (c) fertility and biological analysis of historical records; and (d) physiological sterility, conception and pregnancy.

Of all his works, perhaps that which remains the best known, is the United Nations multilingual demographic dictionary, published in 14 languages and one of the most valuable tools available to the international scientific community.

Paul Vincent was the first demographer to call attention to population momentum in a 1945 publication. He noted that even if replacement fertility were to occur in France and Italy, populations in both countries would continue to increase by a sizeable amount for several decades.

\section{Population momentum}

The notion of population momentum was first described by French demographer Paul Vincent in 1945 (his demographic work is described in Exhibit 4), when he noted that the French and Italian populations would continue to grow even if they immediately had replacement level fertility.

Population momentum gained importance in discussions in the 1960s of population growth in high fertility developing countries. As populations grew faster because of mortality reductions, it was noted that population growth would continue for several decades even if replacement-level fertility 


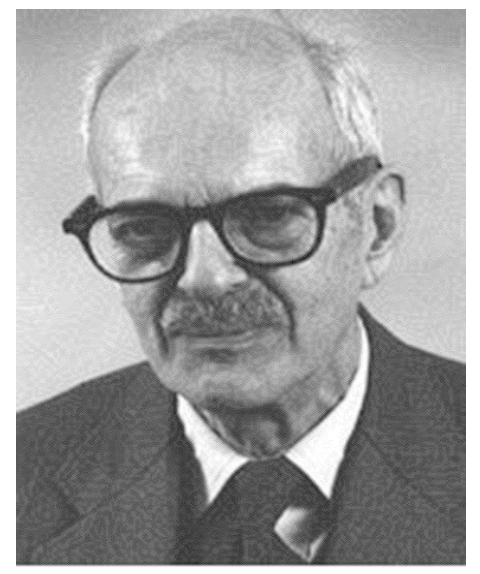

\section{Exhibit 5. Nathan Keyfit,, 1913-2010.}

Nathan Keyfitz, one of the giants of 20th century demography, was born on 29 June 1913 in Montreal, Canada. He graduated from McGill University in 1934 with a degree in mathematics. He began working for Statistics Canada (then called the Dominion Bureau of Statistics) as a research statistician in 1936, where he would remain for 23 years. He rose to the rank of assistant dominion statistician, before beginning a distinguished academic career in 1961.

After graduating in 1952 with his Ph.D. from the University of Chicago, his academic career took him to the University of Toronto, the Université de Montréal, the University of Chicago, the University of California, Berkeley, and Ohio State University before becoming the Andelot Professor of Demography and Sociology at Harvard University from 1972 to 1983.

After achieving emeritus status at Harvard, Keyfitz continued to develop and share his expertise through research, teaching, and advisory roles. In 1983, he became director of the Population Program at the International Institute for Applied Systems Analysis (IIASA) in Vienna, Austria, and established its new international programs while there from 1982 to 1992.

His pioneering work produced hundreds of books and articles in leading journals, and is credited for developing the field of mathematical demography. Keyfitz was a leader in the field of mathematical demography and a pioneer in the application of mathematical tools to the study of population characteristics. Keyfitz early embraced the use of computers in the 1960s to analyze demographic information, and wrote Introduction to the Mathematics of Population in 1968, a text that became a classic in demography.

Building on the work of Paul Vincent, Keyfitz published an article in 1971 that formalized population momentum and noted that a history of high fertility results in a high proportion of women in the childbearing years that ensures high crude birth rates and population growth long after replacement fertility has been achieved.

was achieved. Demographers sometimes refer to a population's "braking distance" to note that longterm population growth typically adds another 50 percent to population size after replacement-level fertility levels is reached in a high-fertility population.

In recent years, it has been observed that sub-replacement fertility populations in Europe have "negative momentum," which means that even if they achieved immediate replacement fertility, they would continue to decline for several decades.

What factors influence population momentum? What are the components of momentum? Are there patterns to population momentum associated with the demographic transition? These are questions that we recently have begun to answer.

In Vincent's 1945 paper, he calculated coefficients of momentum (potential d'accroissement d'une population) by measuring the ratio of the size of the long-run stationary population to the current population size-assuming that replacement fertility is immediately achieved. In Figure 9, the initial observed population is labelled $P$ and the final stationary population is $S_{l}$. Note that Canada's 2011 population has negligible population momentum, as measured by the ratio of $S_{1}$ to $P$. 
In a recent paper, Espenshade and colleagues (2011) calculated population momentum for all United Nations countries. Coefficients ranged from 0.81 for Bulgaria to 1.76 for Oman, illustrating that population momentum can be negative (coefficients less than 1) or large and positive. A coefficient greater than 1.76 would suggest that growth will continue for some time and increase the eventual population size by more than 76 percent, even if replacement-level fertility occurs immediately.

Momentum is an important topic for study. John Bongaarts (2007) estimated that momentum accounts for 58 percent of projected future growth for developing countries over the next century. Negative momentum is now a critical factor for developed countries; eleven European countries, as well as Japan, are projected to decline by more than 10 percent due to negative momentum. Even if fertility were to rise instantly and permanently to replacement level, there are a dozen countries in the world that would still have sizeable population declines in coming decades.

But if we dig deeper into studies of population momentum, we find some confusion about concepts, definitions, and measurement. We start with Nathan Keyfitz's original statements about population momentum (1969, 1971; see Exhibit 5 for a description of Keyfitz's demographic work).

Like Vincent's 1945 work, Keyfitz defined momentum as the ratio of the long-term stationary population to the currently observed population. This is the ratio of $S_{1}$ to $P$, or the ratio of 34.3 million to 34.5 million in Figure 9. For Canada in 2011, this ratio is 0.99, suggesting that there is modest negative momentum in the 2011 population.

Keyfitz relied on stable population theory to make additional derivations. At this point, the research literature over the past thirty years gets confusing. Keyfitz noted that one can calculate the stable population equivalent $Q$ based on current population conditions (Exhibit 6 discusses the stable population equivalent and its interpretation). Keyfitz did not label the ratio of $Q$ to $P$ as a type of population momentum, but later researchers have referred to the $Q / P$ ratio as a special type of momentum, using various terms to describe it (Espenshade et al. 2011: 1585-1587 discuss this research and call it nonstable momentum).

Espenshade et al. (2011) proposed a unified framework for population momentum in an important recent paper. If total momentum is defined as the ratio of $S_{I}$ to $P$, then by definition we can write:

$$
S_{1} / P=Q / P \cdot S_{2} / Q \cdot S_{1} / S_{2} \quad,
$$

where $Q / P$ is nonstable momentum, $S_{2} / Q$ is stable momentum, and $S_{1} / S_{2}$ is a small difference (called the offset factor by Espenshade et al. 2011 and by Blue and Espenshade 2011) due to numerical approximations and theoretical differences.

There is an intuitive explanation for equation (10). Espenshade et al. (2011) note that we can project two populations, the observed population $P$ and the stable population equivalent $Q$ under assumptions of replacement-level fertility, and the eventual population sizes will be $S_{1}$ and $S_{2}$, respectively. This result is shown in Figure 9 as a projection, based on five-year age groups, for Canada's 2011 observed population $P$, as well as for the stable population equivalent $Q$. It is not by chance, however, that $S_{1}$ and $S_{2}$ are very similar. Why does this happen? An intuitive explanation is that total momentum has two components $\left(Q / P\right.$ and $\left.S_{2} / Q\right)$, yet previous work has dealt only with $S_{1} / P$, called total momentum, with limited attention to $Q / P$, which we now call nonstable momentum. The $S_{2} / Q$ ratio, stable momentum, has not been previously considered in our thinking about population momentum.

Let's look at some simple definitions and see what we can learn. If we disentangle total population momentum (the ratio $S_{1} / P$ ), it equals the two ratios stated in equation (10) $-Q / P$ is nonstable momentum and $S_{2} / Q$ is stable momentum. For the equality to hold, then we need to include the ratio $S_{1} / S_{2}$, which, as mentioned above, has been referred to by Espenshade and colleagues as the offset factor. 


\section{Exhibit 6. Stable Population Equivalent Q.}

The idea of a stable population equivalent, the level of the ultimate stable population curve, was first proposed by Nathan Keyfitz (1969) in a paper that derived the population size of a stable age distribution relative to the current observed population size. Keyfitz described the stable population equivalent $Q$ in terms of Leslie (1945) demographic matrices. For 18 five-year age groups, we define matrix $\mathrm{M}$ with the first row for age-specific fertility probabilities and the subdiagonal for survivorship. The five-year age distribution at time 0 is $K^{0} . r$ is the intrinsic rate of natural increase. $H$ is an operator consisting of 18 ones, where $H$ is used to create the total for the vertical vector. With these definitions, $Q$ is calculated as:

$$
Q=\frac{[H] M^{t}\left[K^{0}\right]}{e^{5 r t}}
$$

The expression for $Q$ in equation (6.1) means that the initial population by age, $K^{0}$, is projected forward for $\mathrm{t}$ five-year periods by the matrix $M$ and then backwards an equal amount of time by dividing by $e^{5 r t}$, and the several age groups are added together by $H$. This projection means that any arbitrary age distribution can be projected forward, assuming a fixed schedule for fertility and mortality, until a stable age structure develops. The ultimate stable age structure can then be projected backward, using the same matrix $M$, an equal amount of time. Because the ultimate age structure is stable, the backwards projection produces a stable population equivalent, with size $Q$, for the original time 0 . In practice, any arbitrary age structure will be very close to a stable age distribution within 120 to 150 years. The calculation of $Q$ has been calculated by Keyfitz and others by assuming $t$ equals 50 or 60 (meaning 250 to 300 years for the projection).

Keyfitz (1969: 264-266) pointed out that $Q$ has similar characteristics to R.A. Fisher's (1930) reproductive value $V$, and that both $Q$ and $V$ can be interpreted in terms of the fertility potential for the observed population. Espenshade and Campbell (1977) built on this insight, showing the relationship between Fisher's reproductive value and the stable population equivalent. If $v(x)$ is the reproductive value of a woman at exact age $x$ (Espenshade and Campbell 1977:78), $v(x)$ represents the present value (discounted at rate $r$ ) of the average number of daughters remaining to be born per woman at age $x$. If we define $n(x)$ as the number of females between age $x$ and $x+d x, b$ is the intrinsic birth rate, and $A_{r}$ is the mean of childbearing in the stable population, the stable population equivalent $Q$ can be calculated without a population projection as:

$$
Q=\frac{\int_{\alpha}^{\beta} e^{-r a} p(a) d a}{b A_{r}}
$$

Equation (6.2) offers an explicit expression for the stable population equivalent, and is used for the computations in this paper. This expression complements the interpretation based on equation (6.1). Equation (6.2) tells us that $Q$ is the ultimate population size that the original population would attain if the only source of population change were the contribution of the age structure or nonstable population momentum, as discussed in this paper. When fertility rates increase rapidly in a population with a relatively young age distribution, then the nonstable age distribution contributes to further population increase and the ratio of $Q$ to the observed population $P$ will be greater than one. On the other hand, if fertility rates decrease markedly in a population with a comparatively old age distribution, then the nonstable age distribution contributes to future population decreases and the ratio of $Q$ to $P$ will be less than one. 
What do we know about this offset factor? In practice, the offset factor should be relatively small. Espenshade finds that $S_{1}$ differs from $S_{2}$ by less than 0.5 percent for most countries of the world. Analysis of data for Canada's population over two centuries finds similar results: $S_{1}$ differs from $S_{2}$ by 1 percent or less, and hence, the offset factor is very small for Canada's population using historical data for 1851 to 2011 and population projections to 2061.

When the observed population and its stable population equivalent are projected under conditions of replacement-level fertility, the stationary populations they reach are not necessarily precisely the same. In practice, however, the two stationary population sizes are very close, and the offset factor $S_{1} / S_{2}$ is usually small.

The mathematical expressions for total momentum and its two components, nonstable and stable momentum, are instructive.

Total momentum $S_{1} / P$ is defined as:

$$
S_{1} / P=\int_{0}^{\beta} c(x) / c_{0}(x) \int_{x}^{\beta} p(a) m_{0}(a) d a d x / A_{0}
$$

where $c(x)$ is the observed proportionate age distribution, $c_{0}(x)$ is the stationary proportionate age distribution, $p(a)$ is the survival function, $m_{0}(a)$ is the stationary fertility schedule, $A_{0}$ is the mean age of childbearing in the stationary population, the first integral is from birth to the oldest age of childbearing $(\beta)$, and the second integral is from age $x$ to the oldest age of childbearing $(\beta)$.

The ratio of the size of the stable population equivalent to the observed population depends on the age schedules of mortality and fertility, as well as the observed and stationary age distributions (relative to the mean age of childbearing in stationary population). Total momentum (equation 11) is affected by deviations between the observed population distribution $c(x)$ and the stationary age distribution $c_{0}(x)$ below the oldest age of childbearing. Total momentum is a weighted average of the deviations, where the weights are largest prior to childbearing and are zero by the end of childbearing. So, differences between the observed and stationary age structure for the early years of life, before about age 15 to 20 years, will have a heavy influence on total momentum. If the observed population is already stationary, then there will be no difference between $c(x)$ and $c_{0}(x)$ and, as expected, $S_{1} / P=1.0$ and there is no population momentum.

Nonstable momentum $Q / P$ is defined as:

$$
Q / P=\int_{0}^{\beta} c(x) / c_{r}(x) \int_{x}^{\beta} e^{-r a} p(a) m(a) d a d x / A_{r},
$$

where $c_{r}(x)$ is the stable proportionate age distribution, $r$ is the intrinsic rate of natural increase, $A_{r}$ is the mean age of childbearing in the stable population, and $c(x), p(a), m(a)$, and $\beta$ are the same as defined in equation (11).

Inspection of the expression for nonstable momentum (equation 12) reveals that it is a function of deviations between the current and the implied stable age distribution. Again, the deviations are a weighted average, with the weights being largest for the early years of life and becoming zero by the end of childbearing. Nonstable momentum has been recognized by several researchers: Keyfitz (1969) calculated it without interpreting it as momentum, Bourgeois-Pichat (1971) called the $Q / P$ ratio the "coefficient of inertia," Kim and Schoen (1991: 456) referred to the "the size of the population relative to its stable equivalent," and Feeney (2003: 648) noted that $Q / P$ momentum as a "given age distribution with respect to the given age schedules of fertility and mortality." But nonstable momentum has not had a clear definition or interpretation until recently defined by Espenshade et al. (2011) as one of two components of total population momentum. 
Stable momentum $S_{2} / Q$ is defined as:

$$
S_{2} / Q=\int_{0}^{\beta} c_{r}(x) / c_{0}(x) \int_{x}^{\beta} p(a) m_{0}(a) d a d x / A_{0}
$$

where $c_{0}(x), c_{r}(x), p(a), m_{0}(a), A_{0}$, and $\beta$ are defined in equations (11) and (12).

The expression for stable momentum $S_{2} / Q$, shows that it is based on deviations between the stable and stationary populations. The ratio is a weighted average of deviations, with the weights being constant prior to the beginning of childbearing and decreasing to zero by the end of childbearing. Stable momentum has an interesting relationship with observed levels of childbearing. If replacement-level fertility already exists in the population, then the stable age distribution will be the same as the stationary population, $S_{2} / Q=1.0$, and there is no stable momentum.

Returning to Figure 9, total population momentum, the ratio $S_{I} / P$, equals 0.99 for Canada's 2011 population, which indicates negligible overall population momentum. Looking at the components of momentum, however, shows that the two components largely offset each other. The interesting aspect of Canada's 2011 population is that although total population momentum is small at 0.99 , there are two very different processes affecting population change.

Nonstable momentum, the ratio $Q / P$, is fairly large, with a value of 1.24 in Canada's 2011 population. It reflects the long-term relative change in population size due to differences in the current and implied stable age distribution below the oldest age of childbearing. In Canada's case, fertility has been below replacement for several decades, but the age distribution has not yet adjusted to the new fertility regime. This suggests that there is substantial nonstable momentum in place in the observed age distribution. Once the population becomes relatively stable, then nonstable momentum diminishes.

Stable momentum, the ratio $S_{2} / Q$, is relatively low, with a value of 0.81 for Canada's 2011 population. It reflects the comparison between Canada's 2011 stable age distribution and the eventual stationary age distribution for the earliest part of life. Because fertility has been below replacement, the stable age distribution is older relative to its stationary counterpart.

Table 2. Total, nonstable, and stable momentum for Canada, Europe, and the United States, $2005-2006$.

\begin{tabular}{lccccc}
\hline \multicolumn{1}{c}{ Country/Region } & $\begin{array}{c}\text { (1) Total, S1/P } \\
\text { Ratio }\end{array}$ & $\begin{array}{c}\text { (2) Nonstable, } \\
\text { Q/P Ratio }\end{array}$ & $\begin{array}{c}\text { (3) Stable, S2/Q } \\
\text { Ratio }\end{array}$ & $\begin{array}{c}\text { (4) Nonstable } \\
\text { times Stable }= \\
\text { (2) } \cdot(3)\end{array}$ & $\begin{array}{c}\text { (5) Offset, S1/S2 } \\
\text { Ratio, = (1)/(4) }\end{array}$ \\
\hline Canada, 2006 & 1.02 & 1.35 & 0.76 & 1.03 & 0.99 \\
Europe, 2005 & 0.93 & 1.38 & 0.67 & 0.93 & 1.00 \\
United States, 2005 & 1.11 & 1.16 & 0.96 & 1.11 & 1.00 \\
\hline
\end{tabular}

Source: Europe and United States data are from Espenshade et al. 2011: Table 1. Canada data are from the author's analysis for this paper. See text for description of the components of population momentum.

Using similar calculations for Canada in 2006, we can compare them to calculations made by Espenshade et al. (2011) for Europe and the United States for 2005 (see Table 2). Europe's total momentum is slightly negative, reflecting high nonstable momentum that is counterbalanced by stable momentum. Stable momentum is especially low in Europe because its recent fertility levels are very low, resulting in an implied stable age distribution that is much older than its stationary counterpart. Europe's stable momentum of 0.67 is the lowest for any region in the world. Total momentum for the United States is slightly positive because its stable momentum is close to one and its nonstable momentum is positive. Compared to Europe and the United States, Canada occupies an intermediate level, with offsetting nonstable and stable momentum producing negligible total momentum in 2006. Finally, note that the 


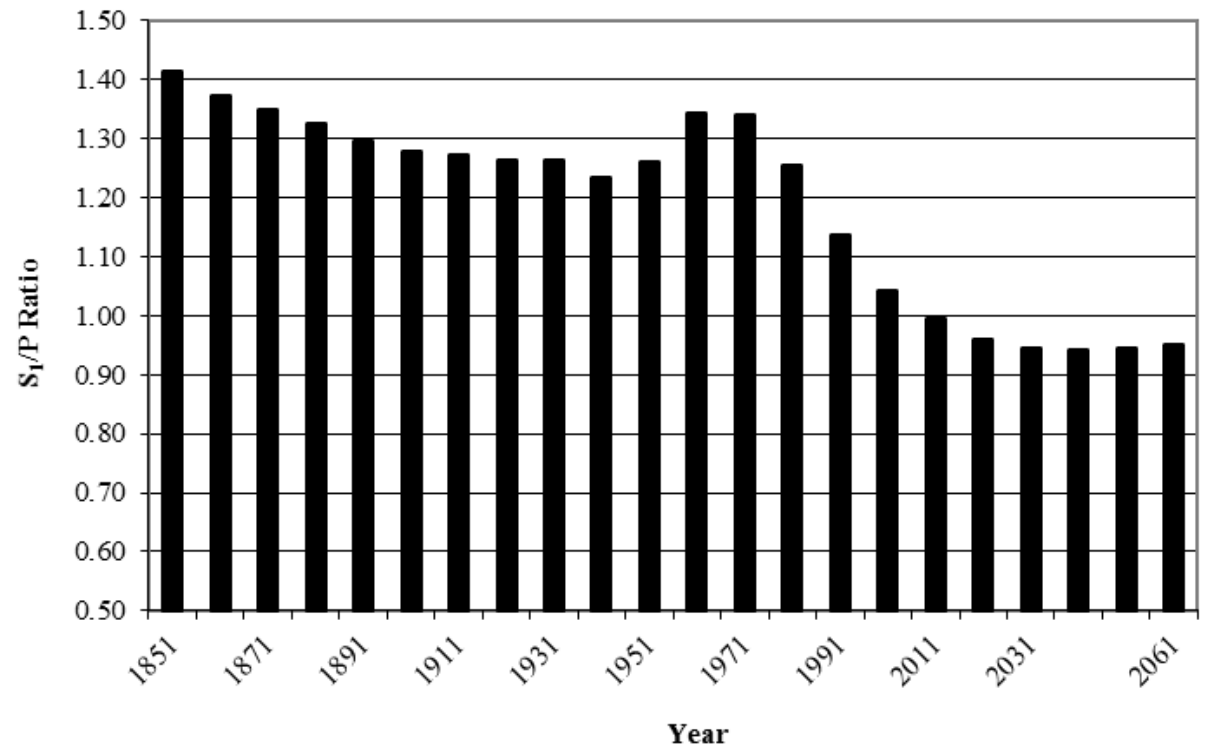

Figure 10. Total population momentum, S1/P Ratio: Canada, 1851-2061.

coefficient for nonstable momentum times stable momentum, shown in column (4), is very close to the value for total momentum. This reflects the fact that the offset factor is close to one.

Figure 10 shows total momentum for Canada from 1851 to 2061. When we compare the longterm stationary population to the observed population, total momentum was very high in Canada from 1851 to 1971 because a previous history of higher fertility produced an age structure that was favourable to continued population growth. In 2011, total momentum declined to less than 1 for the first time. In future years, based on Statistics Canada's population projections, total momentum will remain at levels close to 0.95 , implying long-term population decreases of about 5 percent due to population momentum.

We know, however, that total momentum is affected by two underlying components. What do they show?

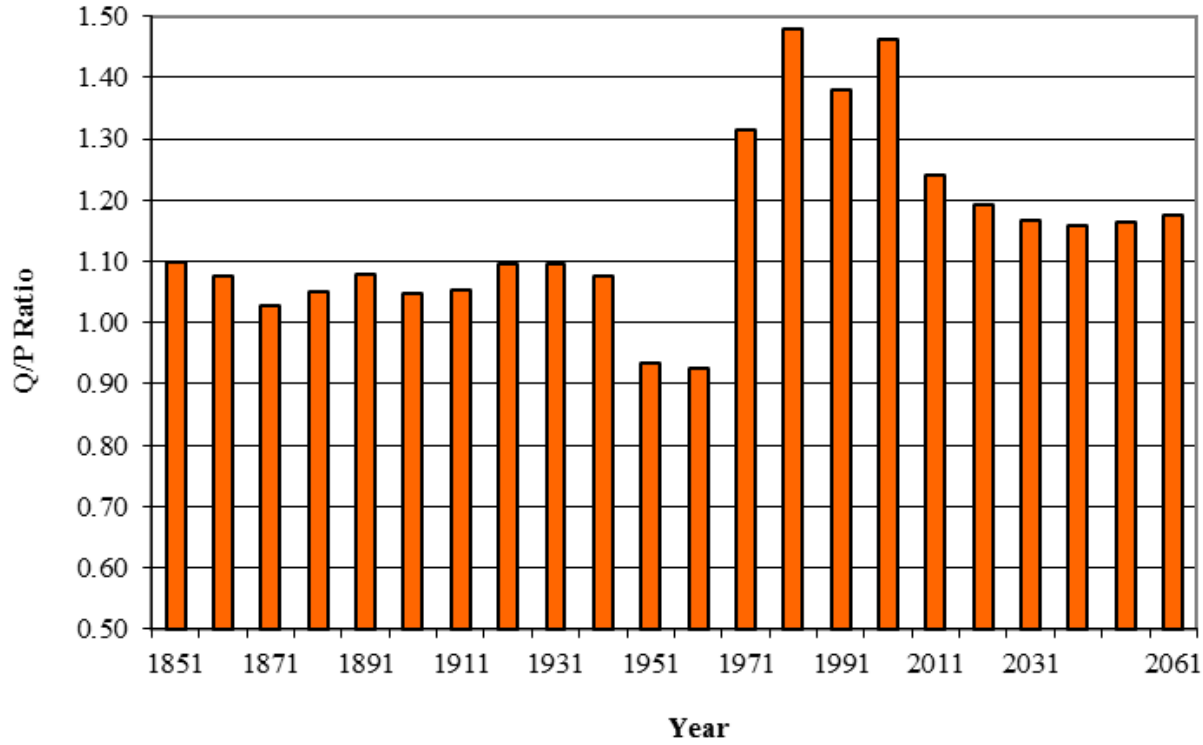

Figure 11. Nonstable population momentum, Q/P Ratio: Canada, 1851-2061. 


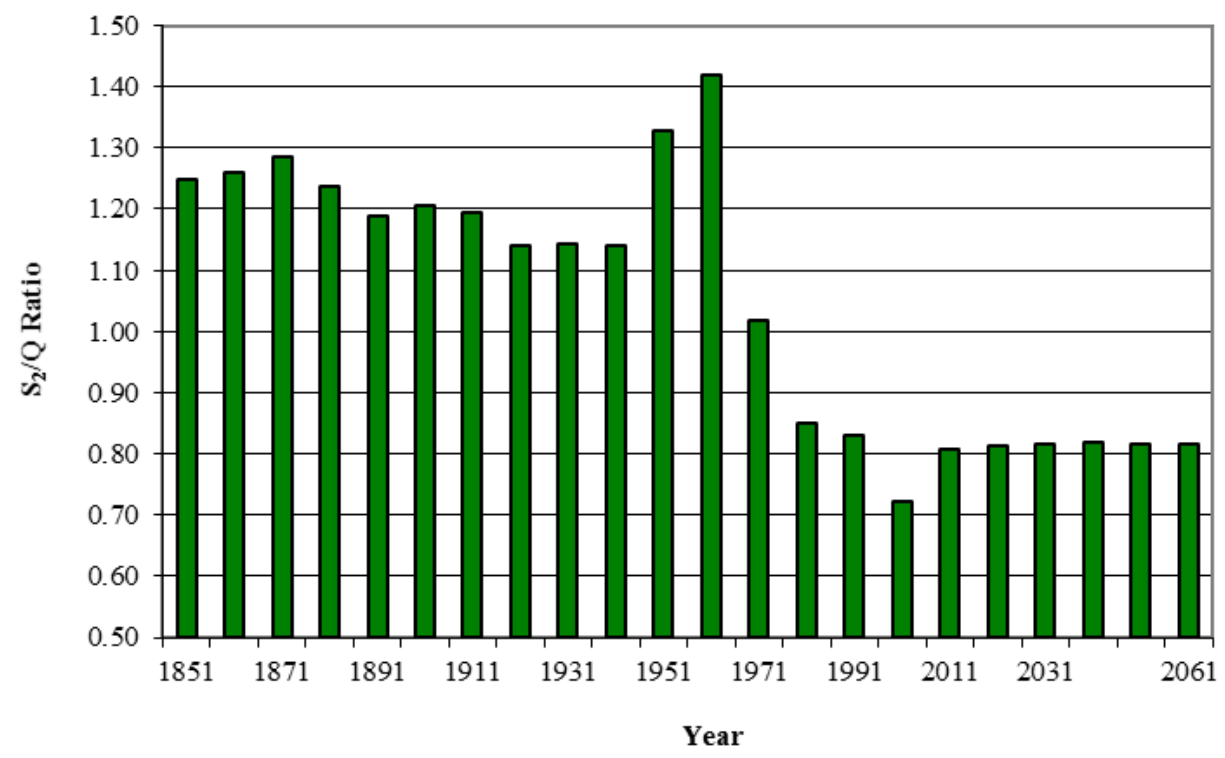

Figure 12. Stable population momentum, $S_{2}$ /P Ratio: Canada, 1851-2061.

First, nonstable momentum reflects the fact that the observed population age structure may differ from the implied stable age distribution. Figure 11 shows nonstable population trends. From 1851 to 1951, nonstable momentum was between 1.0 and 1.1, indicating that the inherent stable age structure was slightly more favourable to continued growth than the observed age distribution. That situation changed greatly with the post-World War II baby boom, which resulted in a large increase in the younger population, driving nonstable momentum down to levels close to 0.9. With rapid fertility declines after the 1960 s, the situation reversed. The observed population in the younger ages is

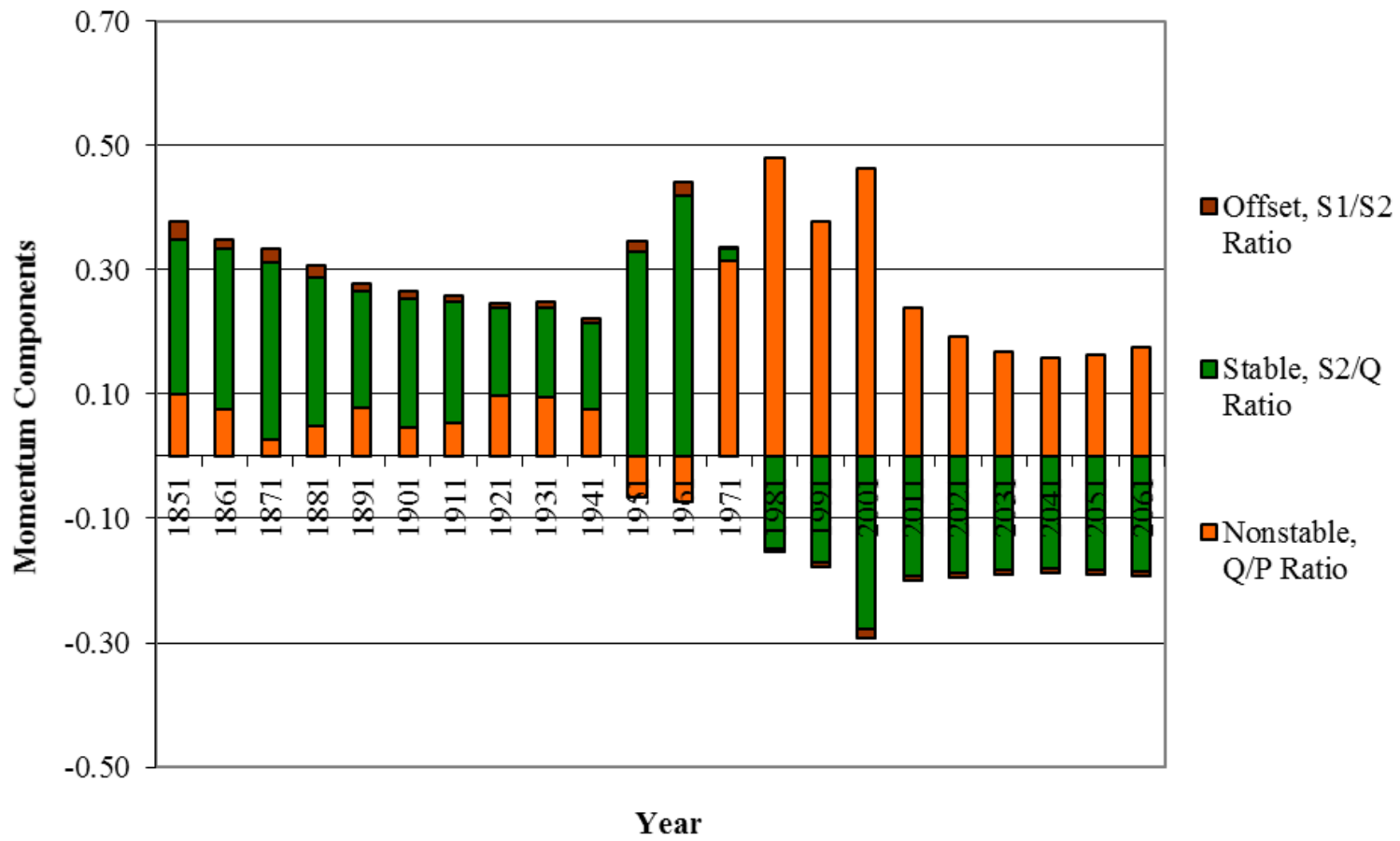

Figure 13. Components of population momentum: Canada, 1851-2061. 
now much below levels implied by the stable age distribution. After nonstable momentum reached unusually high levels above 1.4 between 1981 and 2001, nonstable momentum decreased to 1.24 in 2011 and is projected to remain between 1.1 and 1.2 in coming years.

Stable momentum reflects possible future growth in the stable population if replacement-level fertility were achieved (see Figure 12). Until 1971, stable momentum exceeded 1.0 in Canada. This occurred because the stable age distribution had a younger population than the implied stationary population, insuring future growth if replacement-level fertility were obtained. Following the sizeable fertility reductions in the 1960s and 1970s, stable momentum decreased to 0.72 in 1991 before leaving off at about 0.81 in 2011. Stable momentum is projected to continue at about 0.8 for the foreseeable future.

These changes in the components of momentum over a period of two centuries suggest that it may be useful to show the components together. Figure 13 presents nonstable, stable, and the offset factor as relative deviations from 0 . When the three components are all positive, as they were from 1851 to 1941, they cumulate to total momentum. After 1951, however, the components often counterbalance each other. Until 1941, stable momentum made the largest contribution to total momentum. In 1951 and 1961, with higher fertility nonstable momentum became negative and partially offset some of the large positive effects of nonstable momentum. Since 1981, stable momentum has been negative and nonstable momentum has been positive. At present and projected for the coming decades, the components are largely offsetting and lead to negligible total momentum.

\section{Relationship of demographic transition and population momentum}

What are the expectations regarding components of momentum over the demographic transition? What are the expected associations between fertility levels and momentum components?

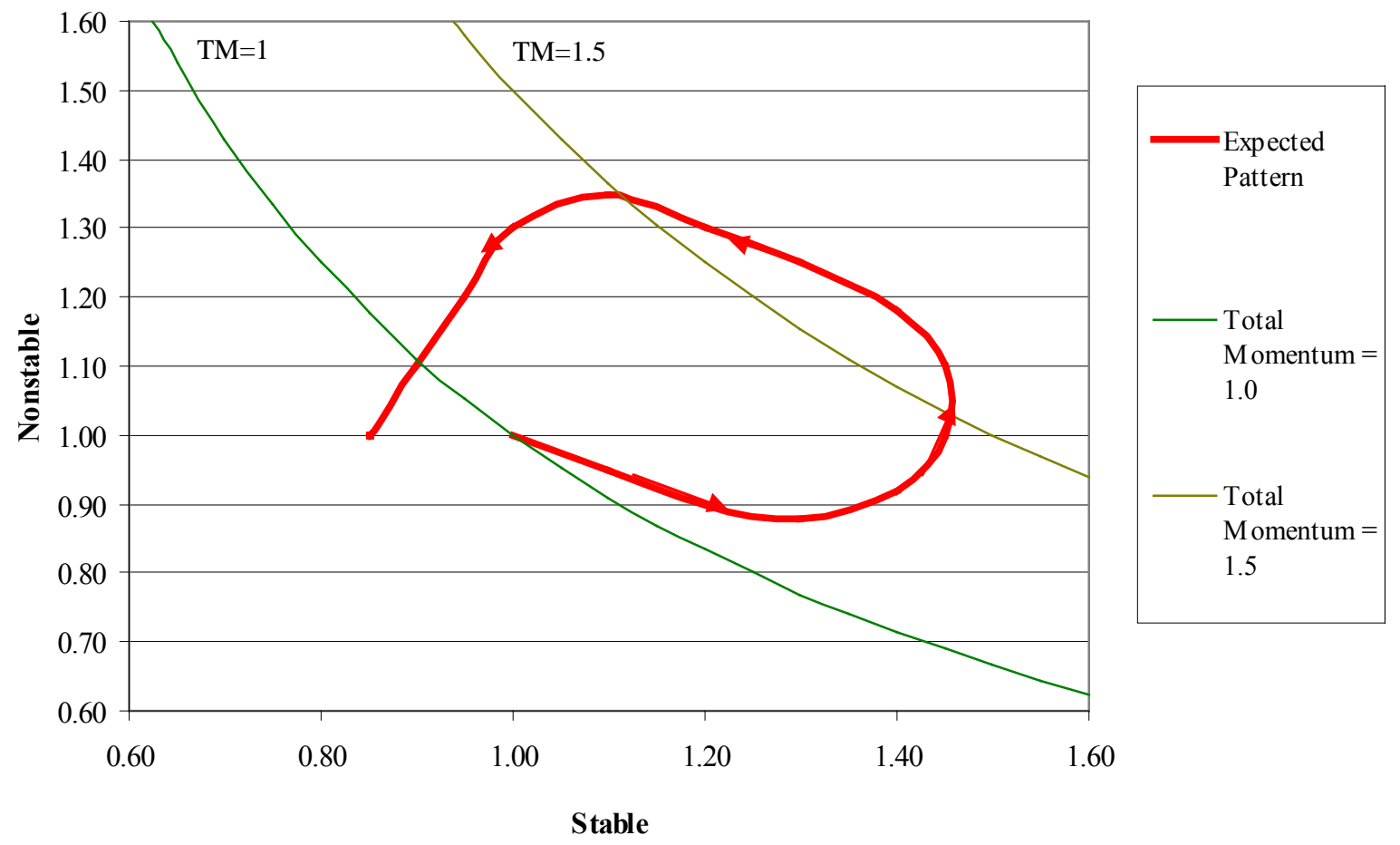

Figure 14. Expected pattern of components of population momentum over the demographic transition in developed countries. Source: Adapted from Blue and Espenshade 2011: Figure 2. 
In terms of stable and nonstable momentum-based on ideas presented in Blue and Espenshade (2011) — we expect that a population's demographic transition will follow roughly a counter-clockwise swirl pattern, as illustrated in Figure 14.

Consider a hypothetical developed low-fertility country. If the pre-transition population is stationary, then there is no momentum, and both stable and nonstable momentum are initially 1 , as noted in the beginning value for the solid circular line. As survival improves and the intrinsic growth rate becomes positive, stable momentum increases while nonstable momentum decreases. This decline in nonstable momentum is the result of an increase in the proportions at the younger ages in the stable age distribution relative to the observed age distribution. A period of rising stable momentum can last for some time, as mortality improvements continue and outpace fertility declines. Then, as the demographic transition enters its later stages, fertility starts to fall more rapidly, causing stable population momentum to peak and begin to fall back toward 1. Nonstable momentum increases rapidly, however, because the observed age distribution partly reflects previously higher fertility. Eventually, if the population returns to replacement-level fertility and stationarity, both stable and nonstable momentum converge again on 1 . If instead the population has prolonged fertility levels below replacement, then stable momentum will move to below 1.

How does Canada compare to this expected pattern? Figure 15 presents Canada's momentum components for 1851 to 2011 and projected to 2061, plotted on a graph similar to that in Figure 14. First of all, we observe that Canada's pattern of momentum components does exhibit a generally counterclockwise pattern from 1851 to 2061. But momentum in 1851 was not centered on 1, because Canada's population had already experienced several decades of mortality decline. The pattern also does not resemble the expected one because the rise and fall of fertility during the 1946-1991 period greatly affected the components of momentum, increasing nonstable momentum and diminishing stable momentum. As shown here, by 2001 nonstable momentum was exceptionally high and stable momentum was low; they counterbalanced each other to produce a level of total momentum that was slightly greater than 1 . With continued fertility below replacement, Canada's future path

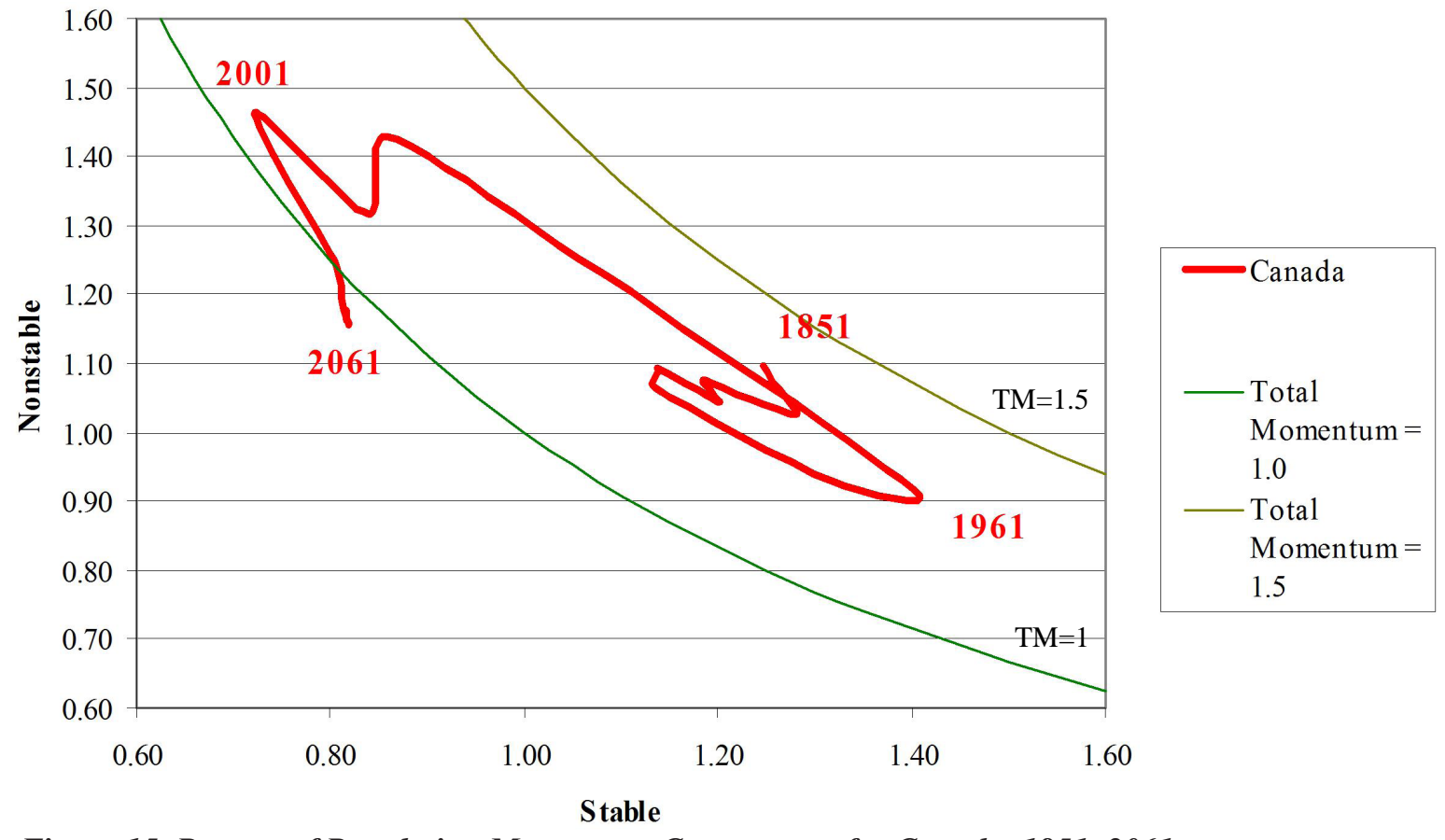

Figure 15. Pattern of Population Momentum Components for Canada, 1851-2061. 
resembles the expected one, with nonstable momentum moving toward 1 and stable momentum remaining below 1. Combined, this means that total momentum is slightly below 1 and is projected to slowly decrease.

\section{How fertility affects population momentum}

Nonstable momentum depends primarily on the relative distribution in the current and implied stable age distributions in the ages before childbearing. If fertility has been increasing in the past twenty years, the proportion of population in the younger years will be higher and there will be relatively low values for nonstable momentum. On the other hand, if fertility has been decreasing in the past two decades, then the proportion of population in the younger years will be lower and there will be relatively high values for nonstable momentum.

The ratio of current to recent total fertility rates (the ratio of current TFR to average TFR over the past 20 years) offers an indicator of past fertility trends. If the ratio exceeds 1.0, then past fertility has been increasing and nonstable momentum would be higher. If the ratio is less than 1.0, then past fertility has been decreasing and nonstable momentum would be lower.

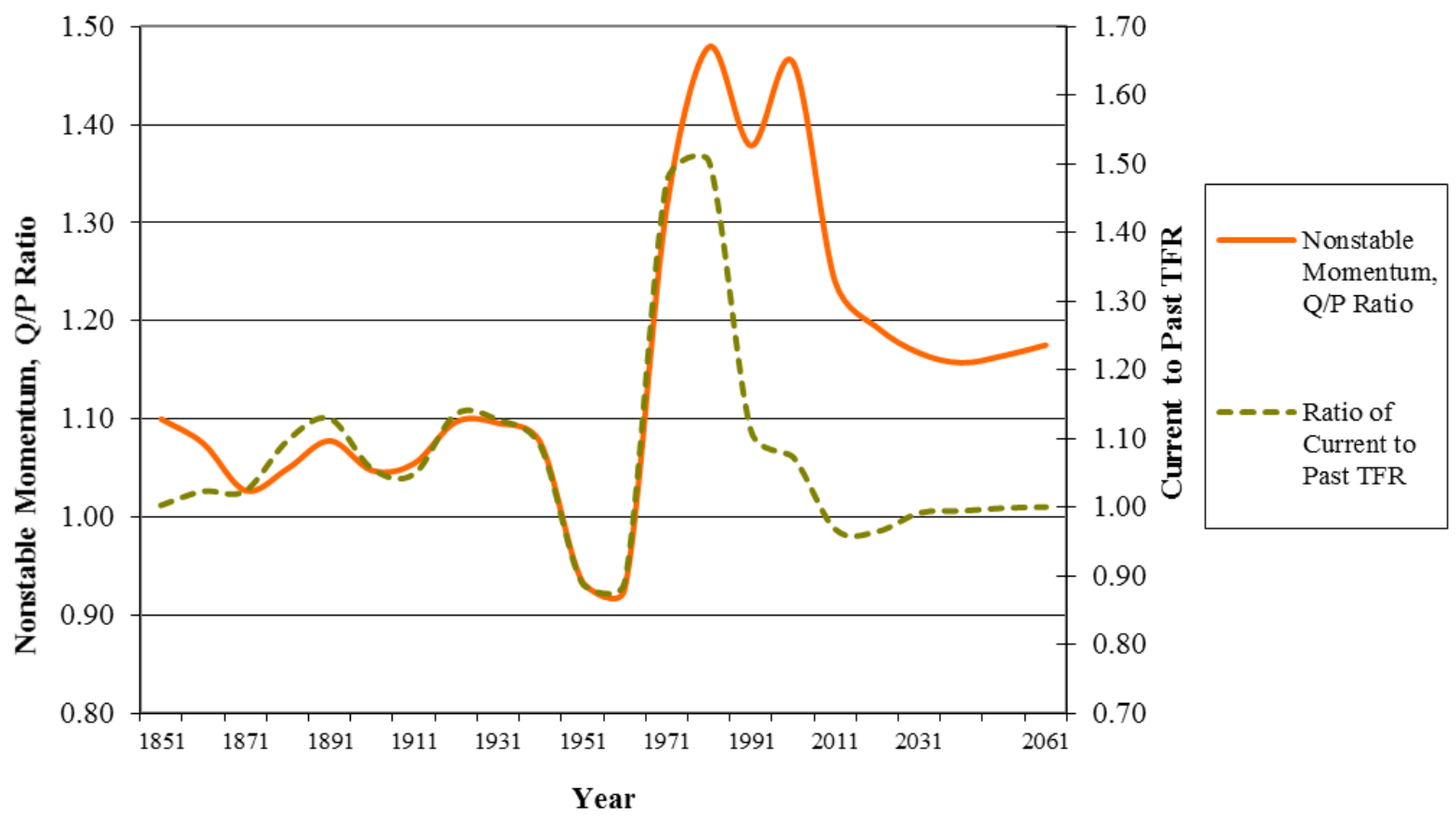

Figure 16. Association of nonstable momentum, the $Q / P$ ratio, and the ratio of current to past total fertility rate: Canada, 1851-2061. Note: The ratio of current to past total fertility rates is defined as the ratio of the current total fertility rate to the average total fertility rate during the past 20 years.

Figure 16 shows the relationship between past fertility and nonstable momentum. The association is as expected (the correlation coefficient equals 0.56). Increases in fertility after World War II were associated with large increases in nonstable momentum. With recent fertility declines, nonstable momentum has been decreasing and is projected to level off at about 1.2.

Stable momentum is influenced by the difference between the population's stable and stationary age distribution in the earlier portion of life. When there is high fertility, the stable age distribution 


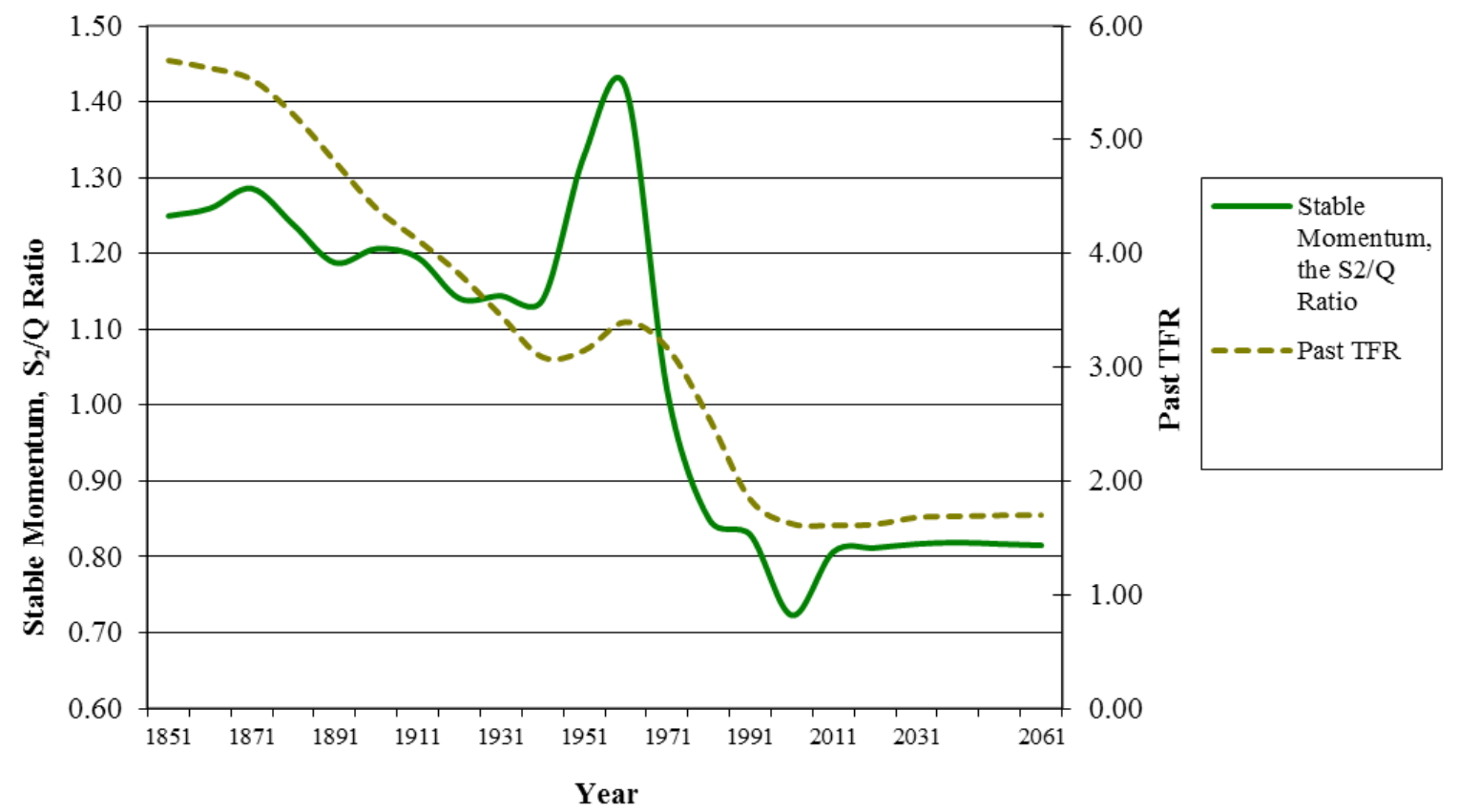

Figure 17. Association of stable momentum, the $S 2 / Q$ ratio, and past total fertility rates: Canada, 18512061. Note: The past total fertility rate is defined as the average total fertility rate during the past 20 years.

will be young relative to its stationary counterpart. And when fertility is substantially below replacement, the stable age distribution will be old relative to its stationary counterpart. If we graph the past TFR (as measured by the average TFR over the past 20 years), we expect stable momentum to vary directly with recent past levels of fertility.

As shown in Figure 17, stable momentum has been higher when recent fertility is higher. As recent fertility falls below replacement levels, stable momentum decreases to levels below 1 . The correlation coefficient equals 0.85 for the association of past fertility and stable momentum.

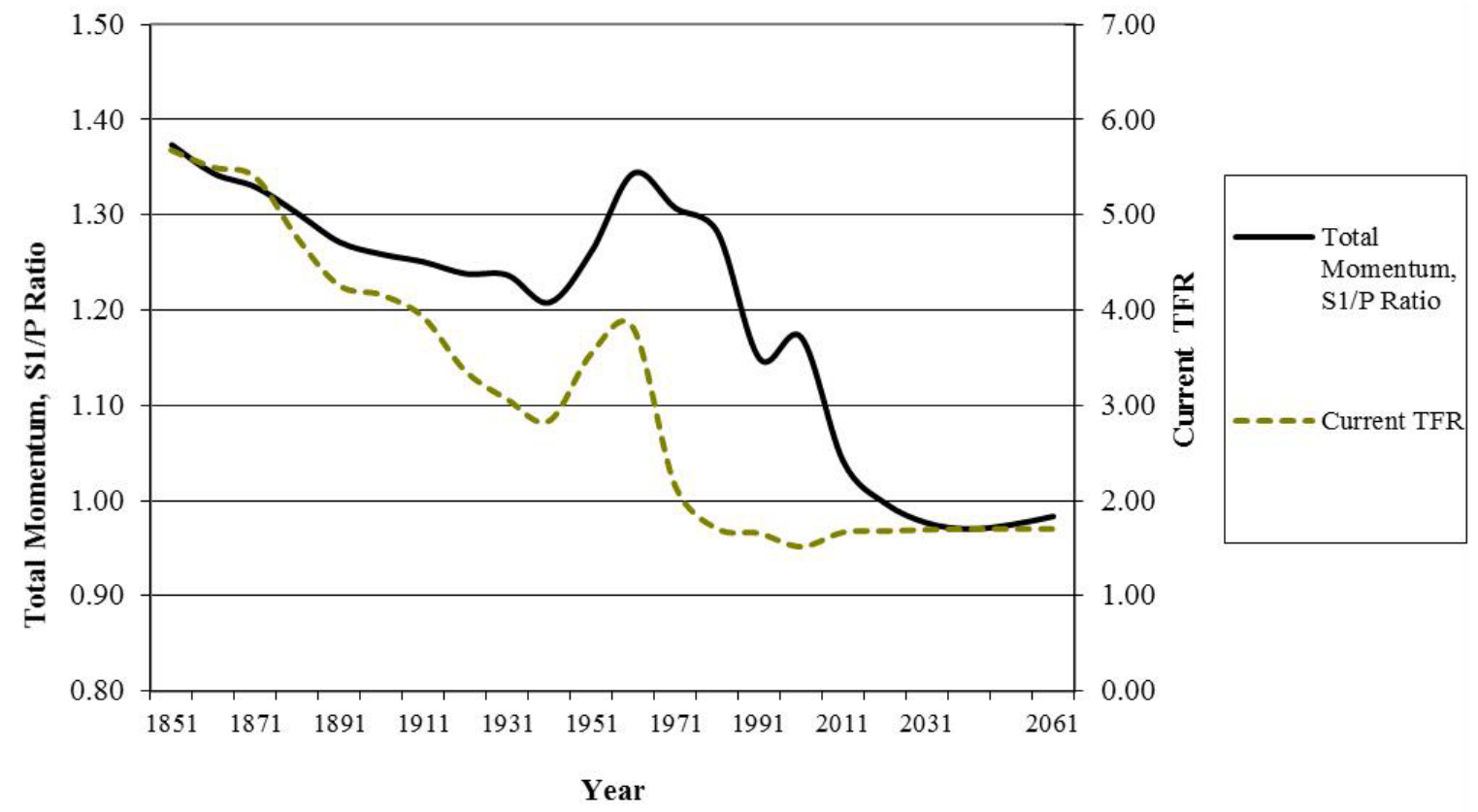

Figure 18. Association of total momentum, $S_{1} / P$ ratio, and current total fertility rate: Canada, 1851-2061. 
Edmonston: Two centuries of demographic change in Canada

Finally, we examine the relationship of fertility and total momentum. Total momentum is affected by the joint combination of nonstable and stable momentum. Overall, total momentum should be associated with levels of current fertility, because total momentum is a function of the ratio of proportions in the observed and implied stationary populations at young ages. This means that total momentum is closely related to very recent levels of fertility.

Figure 18 shows the current TFR and total momentum; the correlation coefficient is 0.77 . When the TFR exceeds replacement levels, population momentum is generally high. When the TFR is less than replacement levels, as it has been for forty years now in Canada, total momentum is lower. As shown in this figure, total momentum has recently dropped to below 1.0, and negative total momentum is likely to persist, according to population projections.

\section{Concluding remarks}

This work on Canada's population raises several questions for further study. First, Canada's population is not closed to international migration. How does migration affect the observed and future age distribution and, in turn, alter intrinsic vital rates and population momentum?

Second, fertility and mortality may differ from the future levels assumed in Statistics Canada's medium-level population projections. How do different assumptions about the future course of survivorship and childbearing affect population momentum?

Third, recent fertility changes and variations in the volume and age distribution of migrants mean that Canada has ripples in its age structure. Successive age cohorts vary in relative size and affect future population age structures, influencing schooling, housing markets, labour force participation, health care, and pension systems. How will different sizes of age cohorts affect different combinations of nonstable and stable momentum?

Finally, disparities between the observed and intrinsic growth rates affect the momentum of population growth. In other words, there is an interesting link between intrinsic vital rates and population momentum. Preston (1986) demonstrated that disparities between actual and intrinsic rates are primarily due to growth-relative to the stable population equivalent-in the ages older than the mean length of a generation, which is very close to the mean age of childbearing. This means that when the intrinsic growth rate is increased or decreased to zero-depending upon the current level of the intrinsic growth rate-resulting growth will occur primarily in the older ages. For Canada, where the intrinsic growth rate is negative and the observed rate of natural increase exceeds the intrinsic growth rate, there is slightly negative population momentum. Because of the relationship established by Preston, negative population momentum in Canada's population would be manifested by decreases in the older population and slight increases in the younger population.

This paper complements a recent short report published by Statistics Canada (2012) that describes major trends in population growth for Canada from 1851 to 2061. This government report, prepared by Statistics Canada's Demography Division's Laurent Martel and Jonathan Chagnon, notes that Canada's population grew slowly in the second half of the 1800s, increased rapidly due to the combination of heavy immigration and high fertility during the first two decades of the 1900s, slowed dramatically after World War I before accelerating in the 1950s and 1960, and has recently diminished to slightly over 1 percent in recent decades. Statistics Canada's population projections for 2011 to 2061 indicate modest population growth that increasingly relies on net immigration rather than natural increase. Their report offers a brief, readable overview of Canada's 
population growth and the joint contribution of natural increase and international migration. On the other hand, the results presented in this paper highlight the more complicated interrelationship of fertility processes and Canada's age distribution, the influence of age structure on observed and intrinsic vital rates, and how differences in observed and stable age structure influence population momentum. As seen in the results of this paper, past fertility largely determines Canada's age distribution, and potential future growth, as indicated by population momentum, is in turn influenced by the current age distribution.

This paper has two recurrent themes. One is the value of looking behind the curtain of observed rates. Although observed vital rates are useful, they often hide important changes. A second theme is the importance of population age structure. We have seen how the history of fertility alters the age distribution, and how current birth and death rates may differ considerably from the intrinsic rates that are derived from the inherent stable age distribution. Examining the components of population momentum presents a new way of thinking about the determinants of overall momentum. In addition, disentangling the two components of momentum demonstrates that previous theoretical work actually fits together in an integrated analytic and empirical framework.

Analyzing the two components - nonstable and stable_-offers a useful factorization of total momentum. At the global level, stable and nonstable momentum are currently equal in importance. This work on Canada's population suggests that the relative importance of nonstable and stable momentum has different patterns over the demographic transition. Canada's current total momentum is close to zero, which exists because positive nonstable momentum is offset by negative stable momentum. Based on current population projections, total population momentum is likely to remain modest for Canada's population in future years.

\section{Acknowledgments}

An earlier version of this paper was presented as the Presidential Address at the annual meetings of the Canadian Population Society, Waterloo, Ontario, May 2012. I appreciate the questions and comments from Canadian Population Society colleagues, which were helpful in revising it for publication. I thank University of Victoria colleagues-especially Thomas Burch, Merwan H. Engineer, Sharon Lee, and Zheng Wu-for their comments and suggestions at a March 2012 seminar in Victoria. My colleagues reminded me that several aspects of demographic methods require more explanation than I first thought. My sincere thanks to Tom Burch for his insightful questions about elements of stable population theory, which suggested new ideas for this paper's interpretations. I also thank two anonymous reviewers for their careful reading and thoughtful suggestions on an earlier draft.

\section{References}

Blue, L., and T.J. Espenshade. 2011. Population Momentum Across the Demographic Transition, Population and Development Review 37(4):721-747.

Bongaarts, J. 2007. Population Growth and Policy Options in the Developing World. Paper presented at the Beijing Forum, Beijing, November. New York: Population Council. 
Edmonston: Two centuries of demographic change in Canada

Bourgeois-Pichat, J. 1971. Stable, semi-stable populations and growth potential. Population Studies $(25,2): 235-254$.

Coale, A.J. 1957. A new method for calculating Lotka's $r$ : The intrinsic rate of growth in a stable population. Population Studies 11(1):92-94.

1974. The history of the human population. Scientific American 231(3, September):40-51.

Cerone, P. 1987. On stable population theory with immigration. Demography 24(August):431-438.

Dublin, L.J., and A.J. Lotka. 1925. On the true rate of natural increase. Journal of the American Statistical Association 20(150):305-339.

Edmonston, B. 2010a. Measuring the effect of immigration on population growth. Chapter 1 in Demographic Aspects of Migration, edited by T. Saltzmann, B. Edmonston, and J. Raymer. Amsterdam: VS Research, Springer-Verlag Publishing.

-2010b. New Estimates for Canada's International Migration. Paper presented to the Netherlands Interdisciplinary Demographic Institute, Den Haag, Netherlands, October.

Espenshade, T.J., L.F. Bouvier, and W.B. Arthur. 1982. Immigration and the stable population model. Demography 19(1):125-133.

Espenshade, T.J., and G. Campbell. 1977. The stable equivalent population, age composition, and Fisher's reproductive value function. Demograpby 14(1):77-86.

Espenshade, T.J., A.S. Olgiati, and S.A. Levin. 2011. On nonstable and stable population momentum. Demography (November 2011):1581-1599.

Feichtinger, G., and G. Steinmann. 1992. Immigration into a population with fertility below replacement level: The case of Germany. Population Studies 46(2):275-284.

Feeney, G. 2003. Momentum of population growth. Encyclopedia of Population, edited by P. Demeny and G. McNicoll. Volume 2. New York: Macmillan Reference. pp. 646-649.

Fisher, R.A. 1930. The Genetical Theory of Natural Selection. Oxford: Oxford University Press (Complete Variorum Edition, with annotations, published by Oxford University Press 1999).

Keyfitz, N. 1950. The growth of Canadian population. Population Studies 4(June):47-63. . 1969. Age Distribution and the Stable Equivalent," Demography 6(3):261-269. 1971. The Momentum of Population Growth,” Demography 8(1):71-80.

Kim, Y.J., and R. Schoen. 1991. Population momentum expresses population aging. Demography 28:159173.

Lachapelle, R. 1990. Le concept de population stable ouverte: application à l'étude des variations de la structure démographique. Cabiers québécois de démographie 19(2):197-214.

Lee, R. 2003. The demographic transition: Three centuries of fundamental change. Journal of Economic Perspectives 17(4):167-190. 
Leslie, P.H. 1945. On the use of matrices in certain population mathematics. Biometrika 33:183-212.

Lotka, A.J. 1934, 1939. Théorie analytique des associations biologique. Two volumes. Paris, France: Hermann, éditeurs des sciences et des arts. Also available as Analytical Theory of Biological Populations. Edited and translated by David P. Smith and Hélène Rossert. Amsterdam: Springer 1998.

Pflaumer, P. 1993. Stationare Bevolkerungen: Anwendungsmoglichkeiten finanzmathematischer und demographischer Methoden zur Analyse des Einflusses von Wanderungen auf die langfristige Bevolkerungsentwicklung.

Sonderforschungsbereich 178, Internationalisierung der Wirtschaft, Diskussionsbeitrage, Serie II, No. 207.

Preston, S.H. 1986. The relation between actual and intrinsic growth rates. Population Studies 40(3):343351.

Ryder, N.B. 1975. Notes on stationary populations. Population Index 41(1):3-28.

1997. Migration and population replacement. Canadian Studies in Population 24(1):1-26.

Statistics Canada. 2010a. Population Projections for Canada, Provinces, and Territories: 2009-2061. Catalogue no. 91-520-X. Ottawa: Minister of Industry.

- 2010b. Population Growth in Canada: From 1851 to 2061. Census in Brief, No. 1, Population and Dwelling Counts 2011. Catalogue no. 98-310-X2011003. Ottawa: Minister of Industry. February.

Vincent, P. 1945. Potential d'accroissement d'une population. Journal de la société de statistique de Paris, $1^{\text {re }}$ Série, Janvier-Février, 86(1-2):16-39. 


\section{Appendix: Computational Methods}

I am convinced that the prime reason that many demographers do not work with applications of stable population models is that there is a lack of working knowledge about computing methods, and their relatively easy use in MS-Excel and other spreadsheet programs. Unfortunately, most work on stable population is presented in integral calculus, with derivations shown in continuous time and other functions. It is perhaps not obvious to most researchers that integral expressions can be rewritten as summations, and integral probabilities can be rewritten as standard five-year demographic formulas. It is also probably not apparent that several computation steps are required for some integral expressions. In order to replicate the results in this paper, this appendix presents the computing formulas for the paper's results. An electronic copy of the MS-Excel spreadsheets, including data, formulas, and results, is available from the author (be@uvic.ca).

The following methods are used in this paper. For each census year, the requisite data include:

1. Population by age and sex, $P_{x}^{F}$ for females and $P_{x}^{M}$ for males, where $N^{F}$ is the total number of females and $N^{M}$ is the total number of males;

2. Age-specific fertility rates for female births $f_{x}^{F}$;

3. Life table person-years lived between $x$ and $x+4$ values by age and sex, $L_{x}^{F}$ for females and $L_{x}^{M}$ for males;

4. Female life expectancy at birth $e_{0}^{F}$, male life expectancy at birth $e_{0}^{M}$; and

5. Sex ratio at birth $S R B$ (assumed to equal 1.045).

Data for 1851-2001 are from Edmonston (2010b). Population projections for 2011 to 2061 are from Statistics Canada (2010).

Calculation of intrinsic vital rates and population momentum involves four series of computations for total momentum, nonstable momentum and intrinsic rates, stable momentum, and the offset factor.

\section{Total momentum}

Step 1. Calculate annual number of female births in the stationary population.

Calculate the net reproduction rate NRR, as $N R R=\sum_{x}^{50}{ }_{5} f_{x}^{F} \bullet_{5} L_{x}^{F}$

Then, replacement-level age-specific fertility rates for female births are: ${ }_{5} f_{x}^{*}=\frac{{ }_{5} f_{x}^{F}}{N R R}$

Calculate the mean age of childbearing in the stationary population:

$$
A^{*}=\sum_{x=15}^{50}(x+2.5) \cdot{ }_{5} f_{x}^{*} \cdot{ }_{5} L_{x}^{F}
$$

Calculate the expected lifetime births that occur above age $x$ in the replacement-level fertility schedule divided by the mean age at childbearing in the stationary population:

$$
w_{x}=\frac{\left(\frac{{ }_{5} L_{x}^{F}}{2} \cdot{ }_{5} f_{x}^{*}+\sum_{y=x+5}^{50}{ }_{5} L_{y}^{F} \cdot{ }_{5} f_{y}^{F}\right)}{A *}
$$


Now, the number of female births in the stationary population is: $B_{S}^{F}=\sum_{x=0}^{50} \frac{{ }_{5} P_{x}^{F}}{L_{x}^{F} / 5} \bullet{ }_{5} w_{x}$

Step 2. Calculate the stationary population, $S_{1}$, when fertility equals replacement-level.

The number of females in the stationary population is: $\quad N_{S}^{F}=B_{S}^{F} \bullet e_{0}^{F}$

The number of males in the stationary population is: $\quad N_{S}^{M}=B_{S}^{F} \bullet S R B \bullet e_{0}^{M}$

And the stationary population is: $\quad S_{1}=N_{S}^{F}+N_{S}^{M}$

Step 3. Calculate total momentum.

Total momentum is the ratio of the stationary population size to the observed population size, or:

\section{Nonstable momentum and intrinsic vital rates}

$$
\frac{S_{1}}{P}=\frac{N_{S}^{F}+N_{S}^{M}}{N^{F}+N^{M}}
$$

\section{$\underline{\text { Step 1. Calculate intrinsic rate of natural increase. }}$}

Calculation of the intrinsic rate of natural increase, $r$, is based on an iterative procedure to solve for $r$ in Lotka's equation:

$$
1=\int_{\alpha}^{\beta} e^{-r a} p(a) m(a) d a
$$

where $\alpha$ is earliest age at childbearing and $\beta$ is the oldest age at childbearing, $p(a)$ is the probability of surviving from birth to age $a$, and $m(a)$ is the probability of bearing female children at age $a$.

The procedure first proposed by Coale (1957) quickly identifies $r$ in several iterations.

Knowing the life table person-years lived between $x$ and $x+5$ for females, ${ }_{5} L_{x}^{F}$, and the rate of bearing female children between ages $x$ and $x+5, f_{x}^{F}$, make an initial calculation of the intrinsic rate of natural increase $r_{0}$ as:

$$
r_{0}=\ln N R R / 27
$$

where $\ln$ NRR is the natural logarithm of the observed net reproduction rate and 27 is an initial value of the mean age of childbearing in the stable population (age 27 is a reasonable first estimate and the correct value for the intrinsic rate of natural increase is calculated no matter what the initial number).

Calculate the amount that the initial value $r_{n}$ - where $r_{n}=r_{0}$ for the first iteration-needs correction as:

$$
y\left(r_{n}\right)=\sum_{x=15,5}^{50} e^{-r_{n}(x+2.5)} L_{x} \bullet f_{x}
$$

and calculate a revised value for the intrinsic rate of natural increase, $r_{n+1}$ as:

$$
r_{n}+1=r_{n}\left[y\left(r_{n}\right)-1\right] / 27
$$

Repeating the calculation of $y\left(r_{n}\right)$ and $r_{n+1}$ three or four times will result in the calculation of $r$ that is correct to five or six significant digits. 
Step 2. Calculate intrinsic birth and death rates and stable age distribution.

Knowing the intrinsic rate of natural increase $r$, the intrinsic birth rate $b$ is:

$$
b=\frac{1}{\sum_{x=0,5}^{80} e^{-r(x+2.5)} \frac{{ }_{5} L_{x}}{l_{0}}}
$$

where $l_{0}$ is the number of persons alive at exact age 0 (called the life table radix and usually set at $100,000)$.

The intrinsic death rate $d$ is the intrinsic birth rate minus the intrinsic rate of natural increase, or $d=b-r$.

If ${ }_{5} C_{x}^{a c t u a l}$ is the actual age distribution of the population, calculated as:

$$
{ }_{5} C_{x}^{\text {actual }, F}=\frac{{ }_{5} P_{x}^{F}}{\sum_{x=0,5}^{85}{ }_{5} P_{x}^{F}}
$$

Then, the stable age distribution of the female population is:

$$
{ }_{5} C_{x}^{\text {stable }, F}=b e^{-r(x+2.5)} \frac{{ }_{5} L_{x}^{F}}{l_{0}}
$$

Step 3. Calculate mean age of childbearing for the stable population:

The mean age of childbearing in the stable population is: $\quad A^{\text {stable }}=\sum_{x=15}^{50}(x+2.5) \bullet_{5} f_{x}^{F} \bullet_{5} L_{x}^{F}$

$\underline{\text { Step 4. Calculate Fisher's (1930) reproductive values. }}$

Fisher's reproductive values, ${ }_{5}$, for the average reproductive value for females for the age interval $x$ to $x+4$, for $x=0$ to 45 , is calculated using the recurrence formula:

$$
{ }_{5} V_{x}=\frac{5}{2}{ }_{5} f_{x}^{F}+\frac{e^{-5 r}{ }_{5} L_{x+5}}{{ }_{5} L_{x}}\left(\frac{5}{2}{ }_{5} f_{x}^{F}+{ }_{5} V_{x+5}\right)
$$

\section{Step 5. Calculate $Q$, the stable population equivalent.}

The size of the female stable equivalent population $Q^{F}$ depends upon Fisher's reproductive values $V_{x}$, the age composition of the female population, and the age schedules of fertility and mortality, calculated as:

$$
Q^{F}=\frac{\sum_{x=0,5}^{50}{ }_{5} P_{x}^{F} V_{x}}{b \cdot A^{\text {stable }}}
$$

The implied number of female births in the stable equivalent population is $Q^{F}$ divided by life expectancy at birth for females: $B_{\text {stable }}^{f}=\frac{Q^{F}}{e_{0}^{F}}$

The implied number of male births is the number of female births times the sex ratio at birth:

$$
B_{\text {stable }}^{M}=B_{\text {stable }}^{F} \cdot S R B
$$


The stable equivalent population for males $Q^{M}$ is the implied number of male births time life expectancy at birth for males.

Then:

$$
Q^{M}=B_{\text {stable }}^{M} \bullet e_{0}^{M}
$$

$$
Q=Q^{F}+Q^{M}
$$

Step 6. Calculate stable population equivalent by age and sex.

The stable equivalent population by age, for females is:

and similarly for males:

$$
{ }_{5} P_{x}^{\text {stable }, F}=Q^{F} \cdot{ }_{5} C_{x}^{\text {stable }, F}
$$

$$
{ }_{5} P_{x}^{\text {stable }, M}=Q^{M} \cdot{ }_{5} C_{x}^{\text {stable }, M}
$$

Step 7. Calculate nonstable momentum, $Q / P$.

Knowing $Q$ and $P$, nonstable momentum equals $Q / P$.

\section{Stable momentum}

Step 1. Calculate annual number of female births in the stationary population.

Start with the stable population by age and sex (see Nonstable Momentum, Step 6). Calculate the net reproduction rate NRR as

$$
N R R=\sum_{x}^{50}{ }_{5} f_{x}^{F} \cdot{ }_{5} L_{x}^{F}
$$

Then, the replacement-level age-specific fertility rates for female births are: ${ }_{5} f_{x}^{*}=\frac{{ }_{5} f_{x}^{F}}{N R R}$

Calculate the mean age of childbearing in the stationary population: $A^{*}=\sum_{x=15}^{50}(x+2.5) \bullet_{5} f_{x}^{*} \bullet_{5} L_{x}^{F}$

Calculate the expected lifetime births that occur above age $\mathrm{x}$ in the replacement-level fertility schedule divided by the mean age at childbearing in the stationary population:

$$
w_{a}=\frac{\left(\frac{{ }_{5} L_{a}^{F}}{2} \cdot f_{a}^{*}+\sum_{y=a+5}^{50}{ }_{5} L_{y}^{F} \cdot f_{j}^{F}\right)}{A^{*}}
$$

Now, the number of female births in the stationary population is:

$$
B_{S}^{F, \text { stable }}=\sum_{a=0}^{50} \frac{{ }_{5} P_{a}^{F, \text { stable }}}{{ }_{5} L_{a}^{F} / 5} \cdot \bullet_{5} w_{a}
$$

Step 2. Calculate stationary population, $\underline{S}_{2}$, when fertility equals replacement-level.

The number of females in the stationary population is: $N_{S}^{F \text {,stable }}=B_{S}^{F \text { stable }} \bullet e_{0}^{F}$

The number of males in the stationary population is: $N_{S}^{M \text {,stable }}=B_{S}^{F, \text { stable }} \cdot S R B \bullet e_{0}^{M}$

The total population size of the stationary population $S_{2}$, based on the implied stable population, is the sum of the number of females and the number of males in the stationary population, or:

$$
S_{2}=N_{S}^{F, \text { stable }}+N_{S}^{M, \text { stable }}
$$


Step 3. Calculate stable momentum as $\underline{S}_{2} L Q$.

Stable momentum is the stationary population calculated from the implied stable population divided by $Q$, or:

$$
\frac{S_{2}}{Q}=\frac{N_{S}^{F, \text { stable }}+N_{S}^{M, \text { stable }}}{Q}
$$

\section{Offset Factor}

Step 1. Calculate offset factor, $S_{1} / S_{2}$.

Knowing $S_{1}$ and $S_{2}$ from above, calculate the offset factor as the ratio $S_{1} / S_{2}$. 